Quaderni di Dipartimento

The Effectiveness of Government Debt for Demand Management: Sensitivity to Monetary Policy Rules

Guido Ascari

(Università di Pavia)

Neil Rankin

(University of York)

\# 133 (11-10)

Dipartimento di economia politica

e metodi quantitativi

Università degli studi di Pavia

Via San Felice, 5

I-27100 Pavia

Novembre 2010 


\section{The Effectiveness of Government Debt for Demand Management: Sensitivity to Monetary Policy Rules*}

\author{
Guido Ascari \\ Dipartimento di Economia Politica \\ e Metodi Quantitativi \\ Universita degli Studi di Pavia \\ Via S. Felice 5 \\ 27100 Pavia \\ Italy
}

Neil Rankin

Department of Economics and Related Studies University of York York YO10 5DD

UK

November 2010

* We thank Jean-Pascal Bénassy, Giancarlo Marini and many seminar participants for helpful comments. Ascari thanks the Alma Mater Ticinensis Foundation for financial support. All errors and opinions are of course our own responsibility. 


\begin{abstract}
We construct a staggered-price dynamic general equilibrium model with overlapping generations based on uncertain lifetimes. Price stickiness plus lack of Ricardian Equivalence could be expected to make an increase in government debt, with associated changes in lumpsum taxation, effective in raising short-run output. However we find this is very sensitive to the monetary policy rule. A permanent increase in debt under a basic Taylor Rule does not raise output. To make debt effective we need either a temporary nominal interest rate peg; or inertia in the rule; or an exogenous money supply policy; or to make the debt increase temporary.
\end{abstract}

\title{
Keywords
}

staggered prices, overlapping generations, government debt, fiscal policy effectiveness, monetary policy rules

\section{JEL Classification}

E62, E63 


\section{Introduction}

The recent economic crisis has witnessed a strong reaction of monetary and fiscal policies to support the economy. In many developed countries, the nominal interest rate reached historically low levels. Unconventional monetary policy measures were implemented, together with large fiscal stimulus packages causing a worsening of the fiscal imbalances. A legacy of the crisis so far has been large deficits and major increases in government debt levels across the world.

Not surprisingly, the academic literature has reacted with a renewed interest in monetary and fiscal policy interactions. The main research question regards the size of the fiscal multiplier depending on the particular fiscal instrument used and on the state of monetary policy. Given the historically low levels of the interest rate particular attention has been devoted to the effects of fiscal policy at a zero interest-rate bound. Eggertson (2009) and Christiano et al (2009) show that the fiscal multiplier can be much larger in this case. More generally, Woodford (2010) provides an insightful critical survey of this recent literature on monetary and fiscal policy interactions (See also Kirsanova et al., 2009).

All the papers surveyed in Woodford (2010), however, employ the canonical 'New Neoclassical Synthesis' (NNS) model for monetary policy analysis. This embodies 'Ricardian Equivalence', so that changes in government debt, when accompanied by changes in lump-sum taxation, have no real effects on the economy. Given the huge increase in debt which has recently occurred in many developed economies, we would like to have a model where government debt - and thus also government budget deficits financed by borrowing has a more interesting and realistic role. In this paper, we thus consider a staggered-price model where Ricardian Equivalence does not hold because of overlapping generations (OLG). We then study monetary and fiscal policy interactions, showing how monetary policy is crucial in shaping the effects of a change in the debt level in this setting. It is worth noting from the outset that, in our framework (and as will be seen), it is the stock of government debt, rather than the size of the deficit, which provides the best single measure of the fiscal stance. Hence we focus on this variable as the primary fiscal instrument. 
A plausible hypothesis about the effect of fiscal policy in such an environment might be as follows. A one-period tax cut financed by an increase in government debt which is then held permanently at its new higher level would stimulate consumption demand. This is for the standard reason that, although agents would rationally anticipate higher future taxes to service the increased debt interest, a proportion of the taxes would fall on agents not yet born, so that currently-alive agents - the recipients of the tax cut - would perceive their lifetime wealth to have risen. In the presence of temporary nominal rigidities, the increase in aggregate demand would then raise output in a typical Keynesian fashion.

Below, we test this hypothesis by constructing a careful dynamic general equilibrium (DGE) model with the aforementioned features. Our purpose is analytical rather than empirical: we are not seeking to match our model quantitatively to the data, but to understand qualitatively, and in depth, the economic forces at work. So far as possible we therefore proceed using algebra rather than numerical simulations, although we also make use of the latter. We start by applying the model to the basic fiscal policy experiment just described. Surprisingly, we do not find that an expansionary short-run effect on output is bound to occur. Indeed, in the baseline version of our analysis, a permanent increase in government debt has no short-run effect on output different from its (relatively insignificant) long-run effect. In other words, it causes neither boom nor slump. Such a policy measure is therefore completely ineffective in raising output. This is despite setting it in a macromodel which deliberately incorporates features which might be expected to give it some leverage.

What is the explanation for this ineffectiveness? We show that the critical factor is the monetary policy regime. In our baseline case, we assume a Taylor Rule for monetary policy, i.e. a rule which makes the nominal interest rate a function of current inflation. ${ }^{1}$ In recent years this has become the standard way to represent monetary policy, for reasons which have been widely discussed. In the case of a basic form of the Taylor Rule and a permanent increase in government debt, it is not possible to leave the parameters of the Taylor Rule unchanged if it is desired to ensure a particular level of long-run inflation, such as zero. The 'intercept' term in the Taylor Rule has to be increased. This adjustment is the prima facie

\footnotetext{
${ }^{1}$ We omit output from the Taylor Rule but its inclusion would not change the result.
} 
source of the neutralising effect on debt. A deeper discussion is presented in the body of the paper.

This result is striking but one may ask how general it is. We hence proceed to explore ways of escaping from it. Firstly we seek to remain in a regime of Taylor Rules. Empirically realistic Taylor Rules allow for 'interest-rate smoothing', such that the nominal interest rate responds only gradually to changes in inflation and output. To study this analytically, we look at a monetary policy in which the nominal interest rate is pegged exogenously at its old level for one or more periods before the basic Taylor Rule takes over. We show that this delay in raising nominal interest rates also delays the rise in the real interest rate, and that this is crucial in enabling government debt to boost aggregate demand. We also allow for gradual adjustment using numerical simulation. We find that when this feature is incorporated, a short-run positive effect of a permanent debt increase on output is again restored. Another possible escape from fiscal ineffectiveness which we consider is to undertake a temporary rather than a permanent increase in government debt. Since the increase is temporary, it is feasible to leave the parameters of the Taylor Rule unchanged while still ensuring zero longrun inflation. We show that a temporary increase in debt does increase short-run output even under the basic Taylor Rule.

A second avenue for exploration is to consider what happens if monetary policy is instead conducted by fixing the money supply, which was the standard assumption until it was displaced by the Taylor Rule. In the later part of the paper we investigate this. A shortrun Keynesian boom once more re-emerges, both in response to a permanent increase in government debt, and also to a temporary increase. A comparison of this monetary regime with the Taylor Rule regime enables us to deepen our understanding of why debt can be ineffective in the latter. Under interest-rate control, the money supply is an endogenous variable. In the face of an increase in debt it jumps downward. This avoids the need for a period of inflation in order to reduce the stock of real money balances to its new long-run equilibrium level, and so avoids the need for a boom in output in order to generate such inflation. 
Other authors have studied fiscal policy, and its interaction with monetary policy, in 'non-Ricardian' DGE models. In particular, various contributions by Leith and Wren Lewis (e.g. 2000, 2006, 2008) have covered and highlighted many issues. To our knowledge, however, the potentially drastic effect of a Taylor Rule on the effectiveness of fiscal policy has not been noted before. A considerable number of papers have examined the determinacy of perfect-foresight equilibrium in DGE models with overlapping generations and money, with or without staggered prices and dynamics of government debt. These include Bénassy (2005, 2007b), Piergallini (2006), Leith and Wren-Lewis (2006) and Leith and von Thadden (2008). Bénassy (2007a) shows that fiscal policy can be effective in a simple Samuelson-type OLG model with one-period price rigidities. Galí et al. (2007) break Ricardian Equivalence by using 'rule-of-thumb' consumers and show that this can explain the econometric evidence of a positive effect of government spending on consumption. Finally, Chadha and Nolan (2007) look at optimal simple monetary and fiscal policy rules in a Blanchard-type framework.

The structure of the paper is as follows. The microeconomic assumptions are presented in Section 2. Section 3 examines the effectiveness of fiscal policy when monetary policy is governed by a Taylor Rule. Section 4 does the same when monetary policy is governed by a money-supply rule, and Section 5 concludes.

\section{Structure of the Model}

The model brings together overlapping price setting in the manner of Calvo (1983) and overlapping generations in the manner of Blanchard (1985). Since we are interested in the qualitative features of such an economy rather than in quantitative matching of the data, we construct the model as sparingly as possible, abstracting from elements which would complicate the dynamics unnecessarily and increase the difficulty of understanding the mechanisms at work. A DGE model with overlapping generations and overlapping price setting already contains numerous intrinsic sources of dynamics. Amongst the elements omitted is capital accumulation. Although this is very commonly studied in conjunction with 
overlapping generations, our focus here is on short- to medium-run time spans during which changes in capital can reasonably be ignored.

\section{(i) Household behaviour}

We use a discrete-time version of Blanchard's (1985) 'perpetual youth' overlapping generations model, in which agents have an exogenous probability, $q(0<q \leq 1)$ of surviving to the next period. This well-known framework conveniently permits the average length of life to be parameterised and includes infinite lives as a special case, namely where $q=1$. In order to have a demand for money and an endogenous supply of labour we include real money balances and labour as arguments of the utility function. However the latter raises a potential difficulty, which is that if leisure is a 'normal' good a fraction of households will have a negative labour supply. To avoid this unsatisfactory implication, we assume a particular utility function which makes labour supply wealth-independent, as discussed below.

Specifically, the household's optimisation problem may be stated as:

maximise $\quad \Sigma_{t=n}^{\infty}(\beta q)^{t-n} \ln \left(C_{s, t}^{1-\delta}\left[M_{s, t} / P_{t}\right]^{\delta}-(\eta / \varepsilon) L_{s, t}^{\varepsilon}\right)$

subject to $P_{t} C_{s, t}+M_{s, t}+B_{s, t}^{N}=(1 / q)\left[M_{s, t-1}+\left(1+i_{t-1}\right) B_{s, t-1}^{N}\right]+W_{t} L_{s, t}+\Pi_{t}-T_{t}$,

$$
\text { for } t=n, \ldots, \infty \text {. }
$$

Here, $n$ is the current period and $s(\leq n)$ is the household's birth-period. $C_{s, t}$ denotes the composite consumption in period $t$ (defined below) of a household born in period $s$; and likewise for money holdings $M_{s, t}$, bond holdings $B_{s, t}^{N}$ and labour supply $L_{s, t} . P_{t}, W_{t}, i_{t}$ indicate the price index, wage, and nominal interest rate, respectively; while $\Pi_{t}, T_{t}$ denote profit receipts from firms and a lump-sum tax, which are assumed age-independent. The parameters satisfy $0<\beta, \delta<1, \varepsilon>1, \eta>0$. Note also that, as in Blanchard (1985), the household receives an 'annuity' at the gross rate $1 / q$ on its total financial wealth if it survives, this wealth passing to the insurance company if it dies. This is an actuarially fair scheme 
which nets out across the population so that in equilibrium the profits of insurance companies are zero.

The utility function (1) is a modified version of one originating with Greenwood, Hercowitz and Huffman (1988) ('GHH'). The modification consists in introducing real money balances. Its implications for behaviour can be seen by deriving the first-order conditions for the above problem, which are as follows:

$$
\begin{gathered}
C_{s, t+1}-\left(P_{t+1} C_{s, t+1} / M_{s, t+1}\right)^{\delta}(\eta / \mathcal{E}) L_{s, t+1}^{\varepsilon}=\beta\left(1+r_{t}\right)\left[C_{s, t}-\left(P_{t} C_{s, t} / M_{s, t}\right)^{\delta}(\eta / \varepsilon) L_{s, t}^{\varepsilon}\right], \\
M_{s, t} / P_{t} C_{s, t}=(1-\delta)^{-1} \delta\left(1+i_{t}\right) / i_{t}, \\
W_{t} / P_{t}=(1-\delta)^{-1}\left(P_{t} C_{s, t} / M_{s, t}\right)^{\delta} \eta L_{s, t}^{\varepsilon-1} .
\end{gathered}
$$

Here, $1+r_{t}$ denotes $\left(1+i_{t}\right) P_{t} / P_{t+1}$, the real interest rate. It is also helpful to define money demand per unit of consumption, $M_{s, t} / P_{t} C_{s, t}$, as $Z_{s, t}$. Then (4) shows that $Z_{s, t}$ is independent of an agent's birth date, $s$, and is a simple decreasing function of the nominal interest rate. From (5) we observe that an agent's labour supply, $L_{s, t}$, does not depend on his consumption except through $Z_{s, t}$. Since $Z_{s, t}$ is the same for all agents, labour supply is therefore also independent of $s$. This is our reason for using GHH preferences: it eliminates the income effect on labour supply which would otherwise arise through the presence of $C_{s, t}$ in (5), $C_{s, t}$ being a variable which is generally increasing with an agent's age, $t-s$. This enables us to avoid the problem of old agents having negative labour supply. ${ }^{2}$

Incorporating wealth-independent labour supply has a cost, however, which is that the utility function is not additively separable. One consequence is that there is a direct positive effect of real balances on labour supply, as can be seen from (5). This is the 'Brock effect' (Brock (1974)). Intuitively, higher holdings of real balances (or higher $Z_{s, t}$, to be precise) give the household an incentive to supply more labour since they complement consumption, raising the marginal utility of the latter. We would not expect this effect to be empirically important but since it is present we should be mindful of it when trying to understand the

\footnotetext{
${ }^{2}$ This issue is discussed in more detail in Ascari and Rankin (2007). The utility function used here is first proposed there.
} 
model's properties. ${ }^{3}$ Non-separability also introduces direct effects of labour supply and of real balances on consumption. This can be seen from the presence of $L_{s, t}$ and $Z_{s, t}$ in (3), which is a version of the Euler equation for consumption. The composite term $Z_{s, t}^{-\delta}(\eta / \mathcal{E}) L_{s, t}^{\varepsilon}$, which is subtracted from both sides of (3), acts like a 'subsistence' level of consumption. In our model the Euler equation can be viewed as determining the growth rate of 'adjusted' consumption, where the latter is defined as actual consumption minus its subsistence level. For the reasons given above, subsistence consumption is independent of age.

Although households of different ages choose the same labour supply and money demand per unit of consumption, in general they will have different lifetime wealth levels and choose different consumption levels. Other things being equal, households who have the good fortune to live longer will have higher wealth, and there will be a distribution of consumption and wealth across the population in any period. For aggregate consumption to be a function only of aggregate wealth (and of relative prices), and thus for it to be independent of the shape of the wealth distribution, it is necessary that an individual household's consumption be linear in its total lifetime wealth. For the utility function (1), we can confirm that this is the case. We thus preserve the feature that made easy aggregation possible in the original Blanchard (1985) paper.

Given the above, we can derive a counterpart of the individual Euler equation, (5), in which individual is replaced by aggregate consumption:

$$
C_{t+1}-Z_{t+1}^{-\delta}(\eta / \varepsilon) L_{t+1}^{\varepsilon}=\beta\left(1+r_{t}\right)\left[C_{t}-Z_{t}^{-\delta}(\eta / \varepsilon) L_{t}^{\varepsilon}\right]-(1-\delta)(1-\beta q)(1 / q-1) V_{t}
$$

Absence of an ' $s$ ' subscript indicates an aggregate value (or, equivalently, an average value, since the population size is one). The relationship of a generic aggregate variable, $X_{t}$, to its constituent individual variables, $X_{s, t}$, is $X_{t}=\Sigma_{s=-\infty}^{t}(1-q) q^{t-s} X_{s, t}$. In the cases of $Z$ and $L$ we have already seen that individual and aggregate values are the same, but this is not generally true in the case of consumption. Nor is it true in the case of financial wealth, $V_{t}$, which, for an individual, is defined as the sum of his money and bond holdings in real terms:

\footnotetext{
${ }^{3}$ Obviously the Brock effect would be absent in a 'cashless' model. However, we need to have money in our model because we want to investigate also the case of a money supply rule, to show how the choice of the monetary policy instrument influences the effect of fiscal policy.
} 


$$
V_{s, t} \equiv(1 / q)\left[M_{s, t-1}+\left(1+i_{t-1}\right) B_{s, t-1}\right] / P_{t}^{4}
$$

The 'aggregate Euler equation', (6), says that the growth rate of aggregate adjusted consumption depends positively on the real interest rate (as in the case of individual adjusted consumption), and (to the extent that $q<1$ ) negatively on aggregate financial wealth. A similar relationship is found in Blanchard (1985) and other applications of the 'perpetual youth' model. The negative influence of financial wealth arises from the 'generational turnover effect'. 5 Such an effect occurs because some old agents are replaced by newborn agents between $t$ and $t+1$, and in general the newborn, since they have no financial wealth, have lower consumption than old agents, who have had time to accumulate it over their lifetimes.

It remains to define composite consumption. We assume a continuum of types of good, indexed by $i \in[0,1]$. The household has CES utility over good types, given by:

$$
C_{s, t}=\left[\int_{0}^{1} C_{i, s, t}^{(\theta-1) / \theta} d i\right]^{\theta /(\theta-1)}, \quad \theta>1 .
$$

The subsidiary part of its optimisation problem is to allocate spending amongst good types to maximise (8) subject to a budget constraint $\int_{0}^{1} P_{i, t} C_{i, s, t} d i=I_{s, t}$, where $I_{s, t}$ is its income available to spend on goods. This leads to the familiar constant-elasticity demand function for good type $i$ :

$$
C_{i, s, t}=\left(P_{i, t} / P_{t}\right)^{-\theta}\left(I_{s, t} / P_{t}\right) \quad \text { where } P_{t} \equiv\left[\int_{0}^{1} P_{i, t}^{1-\theta} d i\right]^{1 /(1-\theta)}
$$

Moreover, at an optimum, $C_{s, t}=I_{s, t} / P_{t}$.

\section{(ii) Firm behaviour}

Firms are monopolistic competitors who produce differentiated goods. As an input they use labour hired in a competitive market. Price staggering is introduced through Calvo's

\footnotetext{
${ }^{4}$ The relationship of aggregate to individual financial wealth is slightly different from the general one just given, being, rather, $(1 / q) V_{t}=\Sigma_{s=-\infty}^{t}(1-q) q^{t-s} V_{s, t}$. This is because we have included the annuity payout in our definition of $V_{s, t}$. Such a payout does not apply to the aggregate variable since it is a redistribution from those who die to those who survive.

${ }^{5}$ This effect is so named by Heijdra and Ligthart (2000).
} 
(1983) mechanism, in which a firm is allowed to adjust its nominal price with probability $1-\alpha$ in any period, while it has to keep it fixed with probability $\alpha$. The optimisation problem of a firm, $i$, which receives the opportunity to adjust its price in period $n$, can thus be stated as:

maximise

$$
E_{n}\left(\Sigma_{t=n}^{\infty} \Delta_{n, t} \Pi_{i, t} / P_{t}\right)
$$

where

$$
\Pi_{i, t}=P_{i, t} Y_{i, t}-W_{t} L_{i, t}
$$

$$
\Delta_{n, t} \equiv\left(1+r_{n}\right)^{-1}\left(1+r_{n+1}\right)^{-1} \ldots\left(1+r_{t-1}\right)^{-1} \quad\left(\text { with } \Delta_{n, n} \equiv 1\right),
$$

subject to

$$
\begin{gathered}
Y_{i, t}=L_{i, t}^{\sigma} \quad 0<\sigma \leq 1, \\
Y_{i, t}=\left(P_{i, t} / P_{t}\right)^{-\theta} Y_{t}, \\
P_{i, t}=P_{i, t-1} \quad \text { with probability } \alpha, \\
\text { for } t=n, \ldots, \infty .
\end{gathered}
$$

Here, $Y_{i, t}, P_{i, t}, L_{i, t}$ are the output, price and labour input of firm $i . W_{t}$ is the wage and $\Delta_{n, t}$ is the discount factor. The demand for good $i$ is given by (12), which is the aggregation across all households of their individual demands, (9), plus the demand from the government (see below). Being infinitesimal relative to the economy as a whole, the firm treats the macro variables which shift its demand function, $Y_{t}$ and $P_{t}$, as given. It also treats $W_{t}$ as given. This is a standard set-up in New Neoclassical Synthesis models. The nominal rigidity combined with monopolistic competition generates the Keynesian feature that output is demanddetermined. This is because firms will always prefer to satisfy any unexpected increase in demand, given that price will have been set above marginal cost as a result of the firm's monopoly power.

Solving the optimisation problem yields the following expression for firm $i$ 's 'new' or 'reset' price:

$$
X_{n}=\left[\frac{\theta}{\theta-1} \frac{\sum_{t=n}^{\infty} \alpha^{t-n} \Delta_{n, t} Y_{t}^{1 / \sigma} W_{t} P_{t}^{\theta / \sigma-1}}{\sum_{t=n}^{\infty} \alpha^{t-n} \Delta_{n, t} Y_{t} P_{t}^{\theta-1}}\right]^{1 /(1-\theta+\theta / \sigma)}
$$


' $X_{n}$ ' denotes the new price set in period $n$. Symmetry amongst firms means that all firms able to change their prices in period $n$ will choose the same new price, so that no ' $i$ ' subscript is needed. (14) is a forward-looking price-setting rule typical of models with Calvo-style price staggering. It says that the new price depends on current and expected future values of aggregate output, the general price level and the wage level.

The general formula for the price index was given in (9). Combining this with the Calvo pricing assumption, we obtain an expression for the price index as a function of current and lagged values of $X_{t}$ :

$$
P_{t}=\left[(1-\alpha) \Sigma_{j=0}^{\infty} \alpha^{j} X_{t-j}^{1-\theta}\right]^{1 /(1-\theta)}
$$

This arises from the fact that, of all the prices in force in period $t$, the fraction which were last reset exactly $j$ periods ago is $(1-\alpha) \alpha$.

\section{(iii) Government behaviour}

The government's budget constraint in nominal terms is:

$$
P_{t}\left(G_{t}-T_{t}\right)+i_{t-1} B_{t-1}^{N}=\left(B_{t}^{N}-B_{t-1}^{N}\right)+\left(M_{t}-M_{t-1}\right)
$$

where $G_{t}$ is purchases of firms' outputs, measured in terms of the composite good. We assume government spending on good $i, G_{i t}$, is determined by a demand function analogous to a household's demand function, (9), and with the same price elasticity.

Defining the real value of government bonds as $B_{t} \equiv B_{t}^{N} / P_{t}$, we can rewrite the budget constraint in real terms as:

$$
G_{t}-T_{t}=B_{t}-\left(1+r_{t-1}\right) B_{t-1}+\left(M_{t}-M_{t-1}\right) / P_{t}
$$

Clearly, only three of the four policy instruments, $\left(G_{t}, T_{t}, B_{t}, M_{t}\right)$, can be chosen independently in any period $t$. Below, we always take $G_{t}$ to be fixed at some exogenous, time-invariant, value, $G$. We take the second independent fiscal instrument to be real government debt, 
inclusive of interest, which we denote as $B_{t}^{\prime} \equiv\left(1+r_{t}\right) B_{t}{ }^{6}$ With either $M_{t}$ or $i_{t}$ being determined by the monetary policy rule (see below), this leaves the lump-sum tax, $T_{t}$, to be determined by (17) as the residual instrument of policy. Such a fiscal regime allows us easily to study the effects of simple types of change in the level of government debt. It is not our goal here to study an empirically 'realistic' fiscal regime: for example, one that incorporates 'automatic fiscal stabilisers', making $G_{t}$ and $T_{t}$ functions of output; or one that involves rules limiting the government deficit or debt levels to some percentage of GDP. Other authors (e.g. Leith and Wren-Lewis, op. cit.) have studied such regimes using models similar to the present one, but these have the drawback that several policy instruments are changing simultaneously, so that numerous effects become intertwined. Instead our objective is to conduct simple fiscal experiments which will elucidate the mechanics of how the macroeconomy is affected. Amongst other things, by choosing the time path of $B_{t}^{\prime}$ exogenously, we remove endogenous changes in the stock of government debt as an additional source of dynamics.

\section{(iv) Market-clearing conditions}

Equilibrium in the goods market requires that:

$$
Y_{t}=C_{t}+G_{t}
$$

This version of the equation is for the composite good, but a similar relationship also holds for every good, $i$.

To write down the condition for equilibrium in the labour market, we first need the aggregate demand for labour. The derivation of this is given in Appendix A. Equating aggregate labour demand to aggregate labour supply, where the latter is given by the inverse of (5) (dropping the ' $s$ ' subscript, for reasons explained), we have:

$$
Y_{t}^{1 / \sigma}\left(P_{t} / \tilde{P}_{t}\right)^{\theta / \sigma}=\left[\eta^{-1}(1-\delta) Z_{t}^{\delta} W_{t} / P_{t}\right]^{1 /(\varepsilon-1)}
$$

\footnotetext{
${ }^{6}$ Government debt should therefore be thought of as 'indexed' debt. More precisely, $B_{t}^{\prime}$ is the number of 'real treasury bills' issued, i.e. it is a promise to deliver $B_{t}^{\prime}$ units of the composite consumption good to the holders of the bonds at the start of period $t+1$.
} 
Here, $\tilde{P}_{t}$ is a price index very similar to $P_{t}$ - see again Appendix A. Below, in order to study the macroeconomic implications of the model, we take a loglinear approximation to its equations. When we do this it turns out that, locally, $\tilde{P}_{t}=P_{t}$, in which case $\tilde{P}_{t}$ drops out of (19). In fact, the aggregate labour demand function on the LHS of (19) is then simply the inverse production function applied to aggregate output, as can easily be seen.

Equilibrium in the bond market requires that the exogenous, government-determined stock of bonds should equal the aggregate demand for them by households. At this point, note that aggregate financial wealth can be written as:

$$
V_{t}=M_{t} / P_{t+1}+B_{t}^{\prime}
$$

The $B_{t}^{\prime}$ component is exogenous under our fiscal policy regime. The other component, $M_{t} / P_{t+1}$, is endogenous, and in money-market equilibrium this must equal money demand as given by the aggregate version of (4).

\section{(v) Steady-state general equilibrium}

It is useful at this point to note some features of the steady-state equilibrium in which all aggregate real variables are constant over time. We consider only steady states with zero inflation since, later, the monetary policy regime will be constructed to ensure long-run price stability.

One important steady-state relationship is:

$$
Y=\left[\frac{\theta \eta}{(\theta-1) \sigma(1-\delta)}\right]^{\sigma /(\sigma-\varepsilon)} Z^{\delta \sigma /(\varepsilon-\sigma)}
$$

(Absence of a time subscript denotes a steady-state value.) From this we see that, in the long run, output is positively related to money demand per unit of consumption, $Z$. The reason for this is the 'Brock effect' mentioned earlier: higher equilibrium real balances raise the marginal utility of consumption, due to non-separability of the utility function, which in turn stimulates households to increase labour supply. Note that in the steady state prices are effectively perfectly flexible, whence steady-state output is determined by the 'supply side' 
of the model. The Brock effect will be weak to the extent that $\delta$ is small, and empirically we would expect $\delta$ to be close to zero. (21) also demonstrates that there is no direct effect of government debt, $B^{\prime}$, on steady-state output. This is despite the fact that under overlapping generations, i.e. $q<1$, government bonds are 'net wealth' for households, i.e. despite the fact that Ricardian Equivalence does not hold (as will be seen in another context below). The explanation is that the 'modified GHH' utility function has eliminated the wealth effect on labour supply. Were such an effect present, an increase in $B^{\prime}$ would directly reduce output by increasing the demand for leisure. In fact, an increase in $B^{\prime}$ does reduce steady-state output in our model, but through the indirect channel of reducing $Z$, as will be shown later.

A second important relationship is the steady-state version of (6), the 'aggregate Euler equation':

$$
1+r=1 / \beta+(1-\delta)(1 / \beta-q)(1 / q-1) V / A .
$$

' $A$ ' here denotes 'adjusted consumption', as defined above. (22) makes clear that, with infinitely-lived agents $(q=1)$, the long-run real interest rate is simply equal to the time preference rate, $1 / \beta-1$. However, with overlapping generations $(q<1)$, the real interest rate exceeds $1 / \beta-1$, the size of the gap depending positively on the ratio of financial assets to adjusted consumption. Intuitively, this is because (22) is the (inverse) 'demand function for financial assets'. A high value of $r$ causes households to choose a positive 'tilt' to their lifetime consumption profiles, and since they have time-invariant labour incomes in a steady state, in order to achieve this they need to accumulate financial assets during their lifetimes. In the aggregate, such behaviour generates a positive demand for financial assets as a store of value, and this demand is increasing in $r$. From (22) we can also see how Ricardian Equivalence fails when $q<1$. Notice that an increase in the stock of government debt, $B^{\prime}$, adds to $V$ and thus raises $r$. (For the moment consider, $M / P$, the other component of $V$, as given.) This means that when $q<1$ government debt affects real variables and so is clearly 'non-neutral'. However, what remains to be seen is the form which this non-neutrality takes in full general equilibrium. 
In a zero-inflation steady state where $B^{\prime}=G=0$, we can derive the following completely reduced-form solution for $r$ :

$$
r=\frac{1}{2}\left\{1 / \beta-1+\chi+\left[(1 / \beta-1+\chi)^{2}+4 \chi\right]^{1 / 2}\right\}
$$

where $\chi \equiv(1 / \beta-q)(1 / q-1) \delta[1-(1-\delta) \sigma(\theta-1) / \theta \varepsilon]^{-1}$. $^{7}$ We can easily see from (23) that when $\chi=0, r=1 / \beta-1$; while when $\chi>0, r>1 / \beta-1$. One special case in which $\chi=0$ is when $q=1$, which is the result noted above. However, another special case in which $\chi=0$ is in the limit as $\delta \rightarrow 0$. It is useful to understand why this occurs. As $\delta \rightarrow 0$, the demand for real balances tends to zero, as is apparent from (4). The equilibrium level of real balances is determined by the demand for them, since even if the nominal money stock $M$ is exogenous what matters is the money stock divided by the price level, and the latter is endogenous. Since we have already assumed that $B^{\prime}=0$ in deriving (23), it can be seen that by letting $\delta$ tend to zero we reduce the total stock of financial assets, $V$, to zero. The earlier equation (22) tells us that, even if $q<1$, in such an extreme case the real interest rate will still simply equal the time preference rate. The intuitive reason for this is that if the supply of financial assets is zero, then for the market to clear the demand for them must also be zero, and to achieve this the real interest rate must be driven down to the time preference rate.

\section{(vi) A loglinearised and partially-reduced form of the model}

In order to permit algebraic investigation of the model's properties, we now loglinearise its equations. The 'reference' steady state about which we take the loglinear approximation is that in which inflation, government spending and government debt are all zero. The value of the real interest rate in this steady state is given by (23). Since it appears frequently as part of the coefficients of the loglinearised equations, we henceforth denote it as $r_{R}$.

Appendix B provides a complete list of the underlying loglinearised equations. In the New Neoclassical Synthesis model to which ours is closely related, the standard way of combining these equations is in the form of a 'New Keynesian Phillips Curve' (NKPC)

\footnotetext{
${ }^{7}$ (23) is the larger of the two solutions of a quadratic equation. We discard the smaller solution because it implies that $r$, and thus $i$, is negative, which is economically meaningless.
} 
equation and an 'IS' equation. So far as possible, we adopt the same approach here. This yields the following equations (derived in Appendix B):

$$
\begin{gathered}
\pi_{t}=\left(1+r_{R}\right)^{-1} \pi_{t+1}+\kappa\left[y_{t}-(\varepsilon / \sigma-1)^{-1} \delta z_{t}\right], \\
{[1-(1-\delta)(1-1 / \theta)] y_{t+1}+\left(1-\zeta^{-1}\right) \delta z_{t+1}} \\
=\beta\left(1+r_{R}\right)\left\{[1-(1-\delta)(1-1 / \theta)] y_{t}+\left(1-\zeta^{-1}\right) \delta z_{t}\right\} \\
+\beta\left(1+r_{R}\right) \zeta^{-1}\left(\hat{i}_{t}-\pi_{t+1}\right)-\beta \chi\left(1+r_{R}^{-1}\right) \zeta^{-1} v_{t}, \\
z_{t}\left(=m_{t}-p_{t}-y_{t}\right)=-r_{R}^{-1} \hat{i}_{t}, \\
v_{t}=m_{t}-p_{t+1}+b_{t}^{\prime} .
\end{gathered}
$$

Unless otherwise stated, lower-case variables are the log-deviations of their upper-case counterparts; e.g. $y_{t} \equiv \ln Y_{t}-\ln Y_{R}$ (where ' $R$ ' denotes the value in the reference steady state). $p_{t}$ is just defined as $\ln P_{t}$ and the rate of inflation as $\pi_{t} \equiv p_{t}-p_{t-1}$. The interest rate variables are defined as $\hat{i}_{t} \equiv \ln \left(1+i_{t}\right)-\ln \left(1+i_{R}\right), \hat{r}_{t} \equiv \ln \left(1+r_{t}\right)-\ln \left(1+r_{R}\right)$. In the case of debt, since $B_{R}^{\prime} \equiv 0$, the log-deviation of $B_{t}^{\prime}$ is not well defined; hence we use $b_{t}^{\prime} \equiv\left(B_{t}^{\prime}-B_{R}^{\prime}\right) / V_{R}$. In the above and henceforth we also set government spending, $G_{t}$, permanently to zero; hence $y_{t}$ and $c_{t}$ are the same variable. Two new composite parameters which appear here are $\kappa \equiv(1-\alpha)\left[\alpha^{-1}-\left(1+r_{R}\right)^{-1}\right](1-\theta+\theta / \sigma)^{-1}(\varepsilon / \sigma-1)$ and $\zeta \equiv[1-(1-\delta)(1-1 / \theta) \sigma / \varepsilon]^{-1}$, which are both positive.

(24) is the NKPC equation for our model, giving inflation as an increasing function of current output and of expected future inflation. It essentially derives from the price-setting and price index equations, (14) and (15), together with the condition for labour market clearing, (19). Compared to the standard model, its novel feature is the inclusion of $z_{t}$, which is the result of the 'Brock effect' of real balances in stimulating labour supply, as discussed earlier. (25) is the IS equation which, as in the related literature, derives from the Euler equation for consumption. One of its distinctive features here is the inclusion of financial wealth, $v_{t}$. This is the result of the 'generational turnover' effect on aggregate consumption, as explained above. Another distinctive feature is the presence of $z_{t}$ and $z_{t+1}$. These are 
additional consequences of non-additively-separable utility, which causes $Z_{t}$ to be a component of 'adjusted consumption', as seen above. Having noted that $z_{t}$ enters the NKPC and IS equations, it is clear that our model, unlike the standard model, cannot be solved without also using the LM equation, given by (26). By substituting the LM equation into (24) and (25) we can eliminate $z_{t}$, introducing further instances of $\hat{i}_{t}$.

The system consisting of (24)-(27) still does not provide a complete description of the economy's time path because it remains to add a monetary policy rule. In the next section we do this using a Taylor Rule for the interest rate, and we study the macroeconomic behaviour which results. In the following section we re-work the analysis assuming instead a simple rule for the money supply.

\section{Fiscal Policy when Monetary Policy is Governed by a Taylor Rule}

The standard way to represent monetary policy in recent years has been to assume that the nominal interest rate is set as a function of the inflation rate and of output. The best known example of such a rule is that of Taylor (1993). In our log-deviation notation, such a rule could be expressed as:

$$
\hat{i}_{t}=\bar{i}+\phi_{\pi} \pi_{t}+\phi_{y} y_{t}
$$

Here, $\phi_{\pi}$ and $\phi_{y}$ are positive feedback parameters. In fact, in what follows, we shall simplify by assuming $\phi_{y}=0$. This reduces the amount of algebra while not affecting the main results.

$\bar{i}$ is the 'intercept term' and represents the value of the (nominal and real) interest rate in a steady state with zero inflation. In the standard, infinite-lives $(q=1)$ model, the steadystate real interest rate $r$ is simply given by $r=1 / \beta-1$, as already noted. Using the 'deviation' measure it is given by $\hat{r}=0$. Zero steady-state inflation is thus obtained by setting $\bar{i}=0$. This can easily be seen from (28), which when $\phi_{y}=0$ implies $\hat{r}(=\hat{i}-\pi)=\bar{i}+\left(\phi_{\pi}-1\right) \pi$ in the steady state. However, in the overlapping-generations $(q<1)$ model, $\hat{r}$ has a more complex set of determinants, amongst which is the level of government debt. The level at which $\bar{i}$ needs to be set in order to ensure zero steady-state inflation is therefore endogenous 
and remains to be calculated: it will simply be whatever is the associated level of the steadystate real interest rate.

\subsection{A permanent debt increase under the basic Taylor Rule}

We first consider a fiscal policy experiment in which the economy is at the reference steady state in period $t=0$, and then in $t=1$ the government raises the stock of debt, $b_{t}^{\prime}$, to some positive value, $b^{\prime}$, and holds it there permanently. This implies that there is a cut in taxation, $\tau_{t}$, in period 1 , and hence a budget deficit which lasts for one period only. Thereafter, taxation is raised to whatever level is required to restore the budget to balance and to keep it there.

We start our analysis of this policy by examining the properties of the new steady state with which the higher debt level is associated. The question of whether and how the economy converges to this steady state is addressed subsequently. The Taylor Rule itself plays no role in determining the steady state other than via our assumption that it is parameterised to ensure steady-state inflation is zero. Hence for now we do not need (28) but we will return to it when considering the dynamics.

Proposition 1. A permanent government debt increase. (i) When $q<1$, a permanently higher government debt increases the steady-state interest rate (real as well as nominal, since inflation is zero) and reduces steady-state output. When $q=1$ these effects are zero, and Ricardian Equivalence holds. (ii) Under a Taylor rule like (28), there are no shortrun effects on output different from the long-run effects, because the system entails an immediate jump to the new steady state with no transitional dynamics.

To prove part (i), first we use the system (24)-(27) to solve for the new steady state values. In doing so, we substitute out $m_{t}-p_{t+1}$ from $v_{t}$ as $z_{t}+y_{t}-\pi_{t+1}$. Setting variables to time-invariant values and $\pi$ to zero, we then have four equations in $(y, \hat{i}, z, v)$. From these we can solve explicitly for the steady-state values $(y, \hat{i})$ as functions of the government debt level, $b^{\prime}$ (see Appendix C):

$$
y=\left\{\beta\left(1+r_{R}\right)-1-\psi+\left[\left[\beta\left(1+r_{R}\right)-1\right] \rho-\psi r_{R}^{-1}-v\right] \xi^{-1} \kappa\right\}^{-1} \psi b^{\prime},
$$




$$
\hat{i}=-\xi^{-1} \kappa\left\{\beta\left(1+r_{R}\right)-1-\psi+\left[\left[\beta\left(1+r_{R}\right)-1\right] \rho-\psi r_{R}^{-1}-v\right] \xi^{-1} \kappa\right\}^{-1} \psi b^{\prime}
$$

Four new composite parameters are introduced in these expressions, namely:

$$
\begin{gathered}
\rho \equiv[1-(1-\delta)(1-1 / \theta)]^{-1}\left(1-\zeta^{-1}\right) \delta r_{R}^{-1}, \quad v \equiv[1-(1-\delta)(1-1 / \theta)]^{-1} \zeta^{-1} \beta\left(1+r_{R}\right) \\
\psi \equiv[1-(1-\delta)(1-1 / \theta)]^{-1} \zeta^{-1}\left[\beta\left(1+r_{R}\right)-1\right], \quad \xi \equiv \kappa(\varepsilon / \sigma-1)^{-1} \delta r_{R}^{-1} .
\end{gathered}
$$

$\rho, v$ and $\xi$ are unambiguously positive. $\psi$ is positive if $q<1$ and zero if $q=1$, since then $1+r_{B}$ $>1 / \beta$ or $=1 / \beta$, respectively, as noted above. The signs of the coefficients on $b^{\prime}$ in (29) and (30) can be seen to depend on the sign of the bracketed term $\{\} ..\{$.$\} is common to both$ expressions and its sign is at first glance ambiguous. However the sign can in fact be resolved to be negative, as we show in Appendix C. Then part (i) of Proposition 1 follows.

That higher government debt should raise the real interest rate is to be expected, since it is a standard result in other overlapping-generations models (e.g. Diamond (1965), Blanchard (1985)). It occurs because, as noted, overlapping generations give rise to a steady-state demand for financial assets which is increasing in the interest rate. Hence when the supply of such assets is expanded by increasing $b^{\prime}$, the interest rate has to rise to clear the asset market. The finding that output falls is perhaps less expected, especially since there is no capital in our model. One might be tempted to guess that it occurs because the increased bond stock, being perceived as 'net wealth' by households, increases the demand for leisure and so reduces labour supply. However, this is not correct, since our use of GHH preferences has removed the wealth effect on labour supply. Instead, the mechanism is the Brock effect: the increased nominal interest rate reduces the equilibrium stock of real money balances, which then reduces the marginal utility of consumption and the incentive to supply labour. We would not expect this effect to be empirically large because $\delta$, the weight on real balances in the utility function, is likely to be close to zero in a realistic calibration.

To prove part (ii), next consider the perfect-foresight transition path to the steady state following the once-and-for-all increase in government debt. Writing the economy's laws of motion in a relatively compact form, we have: 


$$
\begin{gathered}
\pi_{t+1}=\left(1+r_{R}\right)\left[\pi_{t}-\kappa y_{t}-\xi \hat{i}_{t}\right], \\
y_{t+1}-\rho \hat{i}_{t+1}=\beta\left(1+r_{R}\right)\left(y_{t}-\rho \hat{i}_{t}\right)+v\left(\hat{i}_{t}-\pi_{t+1}\right)-\psi\left(y_{t}-r_{R}^{-1} \hat{i}_{t}-\pi_{t+1}+b_{t}^{\prime}\right), \\
\hat{i}_{t}=\bar{i}+\phi_{\pi} \pi_{t} .
\end{gathered}
$$

This system has been obtained from (24)-(27). (The definitions of $(\rho, v, \psi, \xi)$ were given above.) (31) and (32) can be understood as slightly more reduced-form expressions for the NKPC and IS equations, respectively. Relative to the standard versions of these equations, the differences are, firstly, the term in $\psi$ in the IS, which is present when $q<1$ and represents the generational turnover effect; and, secondly, the terms in $\xi$ and $\rho$ in the NKPC and IS (respectively), which arise from non-separability of the utility function.

Part (ii) of Proposition 1 is the benchmark result of the paper and one can see why it holds simply by inspecting the system (31)-(33). Note that (31) and (32), with $\hat{i}_{t}$ governed by (33), constitute a pair of simultaneous first-order difference equations in $\left(\pi_{t}, y_{t}\right) . \pi_{t}$ and $y_{t}$ are both non-predetermined variables. Therefore, for a determinate perfect-foresight equilibrium to exist, we need the two eigenvalues of the system to lie outside the unit circle. We shall discuss further this condition below, but for the moment let us assume that it holds. Now notice that if the economy is initially in a steady state with $b^{\prime}=0$ (and hence $\pi=y=0$ ), and then, in $t=1, b_{t}^{\prime}$ is raised to some positive value $b^{\prime}$ and held there permanently, then there is no time-variation in any exogenous variable of the system over the interval $t=1, \ldots, \infty$. This is because the only exogenous fiscal policy variable in (31)-(32) is $b_{t}^{\prime}$, and by assumption it is held constant at $b^{\prime}$ for $t=1, \ldots, \infty$. It then follows that the economy must jump immediately to its new steady state. This means that the impact effect on output, inflation and all other endogenous variables is the same as the long-run effect. In other words, despite price stickiness and the lack of Ricardian Equivalence, the attempt to give a short-run Keynesian stimulus to output fails. Output moves straight to its new steady-state level which, as seen above, is lower - even if not much lower - than its initial level. The inflation rate, for its part, stays at zero in every period, and hence the price level does not change. 
Everything we have said above holds only if the system admits a determinate perfectforesight equilibrium. Similarly to what was found in some other studies, Proposition 2 states that the determinacy condition is different in an OLG setup, relative to the standard NNS model.

Proposition 2. Determinacy of the perfect-foresight equilibrium. Let $\phi_{y}=0$ in (28). Then the minimum value of $\phi_{\pi}$ needed to induce determinacy is increasing in the degree of price stickiness under overlapping generations $(q<1)$.

As is usual, determinacy requires that the Taylor Rule parameter $\phi_{\pi}$ be sufficiently large. Under infinite lives $(q=1)$, this condition would be simply $\phi_{\pi}>1$. Appendix D, on the other hand, shows that the condition for determinacy under overlapping generations $(q<1)$ can be depicted as follows

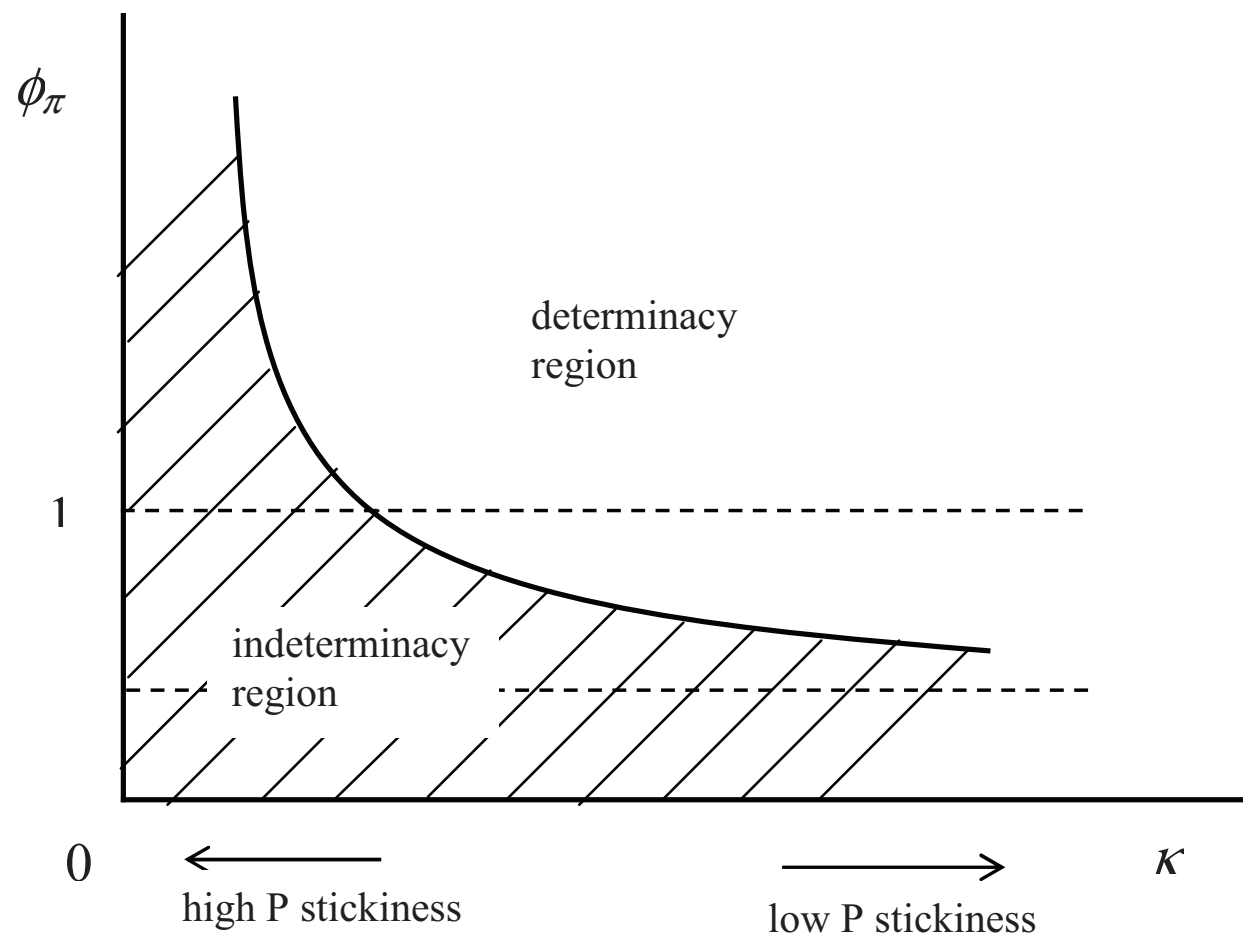

For high degrees of price stickiness (high $\alpha$, and thus low $\kappa$ ), a value of $\phi_{\pi}$ much greater than one may be needed for determinacy. Conversely, for low degrees of price stickiness (low $\alpha$, and thus high $\kappa$ ), a value of $\phi_{\pi}$ less than one may be sufficient. 
In the related literature, Bénassy (2005) finds that the magnitude of the feedback coefficient on inflation becomes irrelevant for determinacy when overlapping generations are introduced. However he assumes a different fiscal policy to ours, in which the total nominal stock of government liabilities (bonds plus money) is held constant over time. Piergallini (2006), meanwhile, finds that overlapping generations relax the normal Taylor Principle, independently of the degree of price stickiness.

To give a specific illustration of the above effects of higher $b_{t}^{\prime}$, we carried out a numerical simulation exercise. For this we used the full non-linear model. This also provides reassurance that the result does not depend on the use of linear approximation. The equations and the calibration of the non-linear model are described in detail in Appendix E. Figure 1 gives the impulse response functions for a policy experiment in which $b_{t}^{\prime}$ is increased permanently from zero to a value equal to $1 \%$ of pre-shock GDP. In addition to confirming the analytical results already discussed, Figure 1 shows that the nominal and real money supply fall. Nevertheless total real financial wealth rises, the fall in real balances being dominated by the increase in government debt.

What is the intuitive explanation for the fiscal ineffectiveness? As we will show subsequently, the result is highly sensitive to the monetary policy regime, and thus to the use of the basic Taylor Rule. Note that under the basic Taylor Rule, the intercept term $\bar{i}$ jumps up immediately when debt is increased. This is needed, as pointed out above, to keep steadystate inflation at zero. Intuitively, then, there is an induced response in the setting of the interest rate which instantly wipes out any positive effect of debt on aggregate demand. Viewed in terms of a simplified version of the IS equation, (32), we can think of 'current' output, $y_{t}$, as being determined by expected future output, $y_{t+1}$, by the real interest rate $\hat{i}_{t}-\pi_{t+1}$ and by government debt $b_{t}^{\prime}$. (For heuristic purposes ignore the terms in $\rho$ and the real-balance term $y_{t}-r_{R}^{-1} \hat{i}_{t}-\pi_{t+1}$.) Moreover we can loosely treat $y_{t+1}$ as exogenous because, relative to current output, future output is less affected by price stickiness and aggregate demand, and more by the economy's supply side. From this simplified perspective, then, a rise in debt will raise current output unless it is offset by a rise in the real interest rate. The latter is what happens in the new steady state. In our policy experiment, however, this rise in 
the real interest rate in fact occurs immediately. What makes this immediate rise in the real interest rate possible, despite the unchanged inflation, is the upward jump in the Taylor Rule's intercept term and thus in the nominal interest rate. Another view of this is the following. Elsewhere it has been shown that the Taylor Rule is effective for stabilising output in the face of random shocks. To use it in this way, the authorities need to adjust the intercept term to match, one-for-one, fluctuations in the 'natural' rate of interest. ${ }^{8}$ The present result shows that this idea remains valid when the shock is a change in government debt, and not just, for example, a change in productivity or preferences. Even though the debt increase is a deliberate fiscal policy change, the Taylor Rule neutralises its effect on output just as if it were a random private-sector disturbance.

\subsection{A permanent debt increase under a Taylor Rule with interest-rate inertia}

If the immediate increase in the Taylor Rule's intercept term, and thus in the nominal interest rate, is what neutralises the output effect of the debt increase, this would suggest that a way of restoring fiscal policy effectiveness is to avoid the increase in the intercept term. It cannot be avoided forever, because if the long-run inflation rate is to remain at zero, there must eventually be a rise in the intercept term, for the reason explained earlier. However, what could be done is that the increase in the nominal interest rate could be delayed. Indeed, this scenario appears to capture well what happened in many western economies in the recent crisis, where an expansionary fiscal policy was assisted by monetary policy keeping the interest rate at historically low levels.

Assume for the moment that monetary policy pegs the nominal interest rate exogenously at its original level for one or more periods at the start of the fiscal expansion, before reverting to the Taylor Rule, (28). This simple assumption about the inertial response of monetary policy allows us to derive analytical results. This is because, if the Taylor Rule is restored from period $t=T$ onwards, we know that the economy will be in its new steady state from period $t=T$ onwards. If the debt increase occurs in period $T-1$, we can then solve backwards in time to find the effect on $y_{T-1}$. Indeed, if the debt increase occurs in period $T-2$,

\footnotetext{
${ }^{8}$ See for example Woodford (2003), Ch. 4.
} 
or $T-3$, etc., we can extend the solution further backwards. The results are summarized in Proposition 3.

Proposition 3. A permanent government debt increase with a delayed interest rate response. Under a temporary interest-rate peg, the debt increase causes a boom in output in the impact period. In the case of a multi-period peg, the size of the impact boom is increasing in the number of periods that the interest rate is pegged, and the boom dies away as the moment for the Taylor Rule to be re-instated approaches.

Although we can derive these results algebraically, for brevity we shall not present the proofs here. ${ }^{9}$ Instead in Figure 2 we provide an illustration from a numerical simulation of the non-linear model (using the same parameter values as before) in which the nominal interest rate is kept fixed for 8 periods. It is clear that, far from immediately jumping upwards to its new, higher, long-run value, the real interest rate under such a policy must fall (relative to its original value) during the period of the interest rate peg, since there is inflation during this period. It is this which avoids the expansionary effect of government debt from being offset, and hence a short-run boom in output does now emerge. Indeed the fall in the real interest rate reinforces the boom. Referring to our earlier intuitive discussion in terms of a simplified IS relationship, the fact that the real interest rate is prevented from immediately attaining its new, higher, steady-state value is what permits the increase in debt to boost current consumption demand and thus output.

More generally, it has often been noted that in practice central banks typically adjust interest rates only gradually. Accordingly, empirical studies of interest-rate setting find that, in place of (28), a relationship such as

$$
\hat{i}_{t}=(1-\chi)\left(\bar{i}+\phi_{\pi} \pi_{t}+\phi_{y} y_{t}\right)+\chi \hat{i}_{t-1} \quad(0 \leq \chi<1)
$$

fits the data better, where $\chi$ captures the degree of nominal interest-rate inertia.

The use of a Taylor Rule with inertia introduces a predetermined state variable into the model. Its laws of motion are now given by (31), (32) and (34) (in which we shall again set $\phi_{y}$ $=0)$. The dynamics become third-order, and thus relatively complicated. Numerical

\footnotetext{
${ }^{9}$ They are available upon request.
} 
simulation is the easiest way of investigating the properties of such a system quickly. Accordingly, Figure 3 shows a simulation of the effects of the same permanent debt increase as before, for the case where $\chi=0.9$. It can be seen that a short-run boom in output occurs in this case too, dying away asymptotically. Again, the key to 'releasing' this expansionary effect is the sluggish response of the nominal interest rate, and thus also of the real interest rate. Inertia in the Taylor Rule thus makes a crucial difference to the effectiveness of government debt in influencing aggregate demand. Investigation of other parameter values shows that the inertia needs to be substantial in order for this to work. For example, if $\chi=$ 0.3 , then there is no short-run boom: there is merely a delay in output falling from its original level to its new, slightly lower, steady-state level.

Therefore, despite the negative 'benchmark' result in Proposition 1, our model can still explain how the 'fiscal stimulus' policy pursued by many governments in the 2008-9 'credit crunch' recession almost certainly did contribute to alleviating that recession. During the recession, central banks cooperated with governments to keep the nominal interest rate pegged at a value close to zero, rather than raising it in the face of a big increase in government debt. Had they done the latter, the expansionary benefits would have been completely lost.

\subsection{A temporary debt increase under the basic Taylor Rule}

If the aim of fiscal policy is to stabilise output fluctuations in the face of temporary business cycle shocks, then any increase in the level of government debt should be temporary, rather than permanent. The government will presumably want to bring debt back to its original level, or to some target level, in the long run. Temporary changes in debt might therefore be a more relevant policy measure to consider than permanent changes.

There is also a technical reason why a temporary increase in debt offers some potential for escaping from the ineffectiveness result of Proposition 1. With a permanent increase, the intercept term in the Taylor Rule eventually has to be increased if we want to keep long-run inflation at zero. However, if the increase is only temporary, it is possible to leave the intercept term unchanged and still ensure zero steady-state inflation. This suggests that a 
temporary increase in debt, under an unchanged Taylor Rule, might also succeed in raising output.

Proposition 4. A one-period government debt increase. An increase in $b_{t}^{\prime}$ which lasts for only one period will cause a temporary (one-period) increase in output and inflation, if all the parameters of the Taylor Rule are left unchanged.

Suppose debt is increased from zero to some positive value in period $t$, and then is returned to zero in period $t+1$ and held there ever after. It follows that, for period $t+1$ onwards, the economy is back in the original steady state from which it started in period $t-1$, before the debt increase. In other words period- $(t+1)$ and later variables are unaffected by a one-period debt increase and only period- $t$ variables will change. This is due to the completely 'forward-looking' nature of the equilibrium under a Taylor Rule. Look again at the economy's laws of motion, (31)-(33). By the argument just made we may treat $\left(\pi_{t+1}, y_{t+1}, \hat{i}_{t+1}\right)$ as exogenous in these. The equilibrium in period $t$ then reduces to the solution of two equations in which the only unknowns are $\left(\pi_{t}, y_{t}\right)$. These are shown below as (35) and (36). They are obtained by substituting out $\hat{i}_{t}$ as $\phi_{\pi} \pi_{t}$ from (31) and (32) and regrouping terms.

$$
\begin{gathered}
\pi_{t+1}=\left(1+r_{R}\right)\left[\left(1-\xi \phi_{\pi}\right) \pi_{t}-\kappa y_{t}\right] \\
y_{t+1}+\left(v-\psi-\rho \phi_{\pi}\right) \pi_{t+1} \\
=\left[\beta\left(1+r_{R}\right)-\psi\right] y_{t}+\left[v+\psi r_{R}^{-1}-\beta\left(1+r_{R}\right) \rho\right] \phi_{\pi} \pi_{t}-\psi b_{t}^{\prime}
\end{gathered}
$$

By the reasoning above, we observe that the left-hand sides of these equations are exogenous.

(35) and (36) can be loosely interpreted as 'short-run aggregate supply' (SRAS) and 'short-run aggregate demand' (SRAD) equations, respectively. This is because (35) still mainly derives from the 'NKPC' equation and (36) still mainly derives from the 'IS' equation. Although some of the composite coefficients on the right-hand-side variables are at first sight ambiguous in sign, in fact we may resolve all of them to be positive under reasonable assumptions, as Appendix F demonstrates. These equations can then be depicted in a familiar textbook manner: 


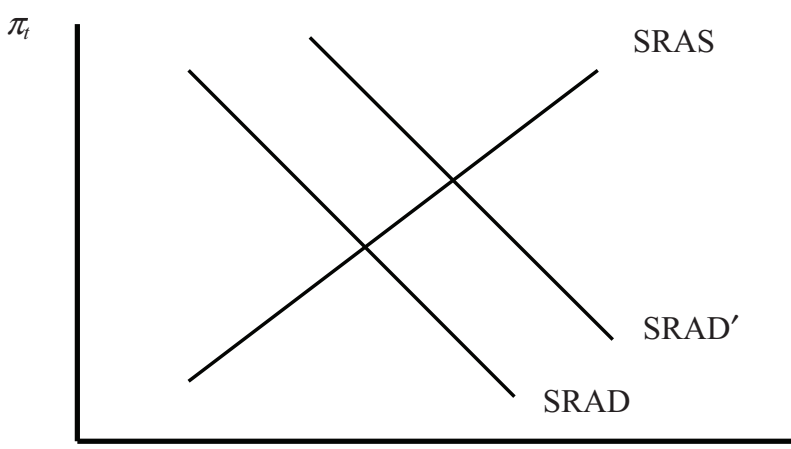

It is now easy to see that, so long as $q<1$ and thus $\psi>0$, an increase in $b_{t}^{\prime}$ will shift the SRAD curve to the right, and so will raise current output and inflation.

Why does a temporary debt increase succeed where a permanent one failed? The reason is that in this case there is no offsetting increase in the Taylor Rule's intercept term. Nevertheless, the nominal interest rate will still rise (if we assume $\phi_{\pi}>1$; see again Proposition 2), because $\pi_{t}$ rises. However, it will not rise by enough to choke off the boom. It would of course be possible to use monetary policy to choke off the boom, by accompanying the fiscal expansion by a one-period increase in the Taylor Rule's intercept term, $\bar{i}_{t}$. The point here is simply that it is now not necessary to increase the intercept term in order to ensure zero long-run inflation.

To study a temporary increase in debt which lasts for more than one period, we turn to numerical simulation. As above, the parameters of the Taylor Rule are left completely unchanged. Figure 4 shows the case of an increase in debt which lasts for exactly four periods. All other parameter values are identical to those in the earlier non-linear simulations. Again there is a short-run boom in output and inflation. An interesting feature is that the time path of output is hump-shaped, despite the fact that the level of debt is constant during the first four periods. By comparing it with the same simulation for a one-period debt increase (not shown), we can also say that the size of the boom in the first period is larger.

Making the increase in government debt temporary thus provides a second way to escape from our earlier fiscal ineffectiveness result. As argued above, this point is also important for practical policy, because governments are likely to want to use the debt to smooth out the effects of temporary business cycle shocks, and thus to make temporary 
changes to the debt itself. The study of permanent changes nevertheless remains important to the extent that governments may not always be able to credibly commit to making only temporary changes. In practice, changes in debt have often been very long-lasting.

\section{Fiscal Policy When Monetary Policy is Governed by a Money-Supply Rule}

In this section, we replace the Taylor Rule by a rule which makes the monetary growth rate the exogenous instrument of monetary policy:

$$
\mu_{t} \equiv m_{t}-m_{t-1}
$$

Presently we will assume that $\mu_{t}=0$ in all periods, i.e. that the money supply is pegged at a constant value; but to show how $\mu_{t}$ enters the equations we begin with the more general case.

The economy's laws of motion under this regime are still given by (31) and (32). However the Taylor Rule, (33), is replaced by:

$$
\hat{i}_{t+1}=\hat{i}_{t}+r_{R}\left(y_{t+1}-y_{t}+\pi_{t+1}-\hat{\mu}_{t+1}\right) .
$$

This is just the first-differenced version of the LM equation, (26). We now note that (31), (32) and (37) constitute a system of three simultaneous first-order difference equations, i.e. a third-order system. The variables in this system, $\left(\pi_{t}, y_{t}, \hat{i}_{t}\right)$, all appear at first sight to be nonpredetermined, as was the case under a Taylor Rule. However, although this is true of each variable individually, it is not true of them jointly. To see this, add $p_{t-1}$ to both sides of (26) and rearrange to obtain:

$$
\pi_{t}+y_{t}-r_{R}^{-1} \hat{i}_{t}=m_{t}-p_{t-1}
$$

As of period $t$, the RHS of (38) is clearly predetermined, and thus a linear combination of $(\pi$, $\left.y_{t}, \hat{i}_{t}\right)$ is predetermined. This means there are only two degrees of freedom in the way the state variables can 'jump' if an unexpected shock occurs. Our third-order system is hence equivalent to a system with one predetermined and two non-predetermined state variables. The fact that there is now a predetermined variable means that the economy will not in 
general jump straight to its new steady state when there is a permanent shock. This already suggests that, under a money supply rule, the short-run impact of an increase in government debt is unlikely to be the same as the long-run impact. More precisely, we can show that:

Proposition 5. A permanent government debt increase under a money supply rule. If the money supply is held constant, then: (i) a determinate, bounded, perfect-foresight solution exists with no additional parameter restrictions; (ii) a permanent debt increase unambiguously raises short-run output, relative both to its new steady-state value and to its original steady-state value.

To prove part (i), we need to demonstrate that, under a regime of a constant money supply $\left(\hat{\mu}_{t}=0\right.$ for all $t$ ), of the three eigenvalues of the system (31), (32) and (37), two lie outside the unit circle and one lies inside. Moreover we can show that the stable eigenvalue lies in the interval $(0,1)$. Hence, following a shock, the economy converges gradually and monotonically to its new steady state. To prove part (ii), we need to show that the multiplier

$$
\frac{d\left(y_{1}-y\right)}{d b^{\prime}}
$$

giving the impact effect of a permanent increase in debt on output relative to its effect on new steady-state output, is positive. Recall from Proposition 1 that, in the case of the Taylor Rule, this multiplier equals zero. In the present case we can show that it is positive with only mild extra conditions as sufficient conditions (in particular, that $\delta$ be close to zero). Under this more traditional monetary policy regime, therefore, a permanent debt increase unambiguously causes a boom. ${ }^{10}$

An illustration of this is provided in Figure 5. Here we chart the outcomes of a numerical simulation identical to that used for Figure 1, except that a constant money supply replaces the Taylor Rule. It is interesting to note that the nominal interest rate 'overshoots' its new steady-state level. This is in contrast to what happens under the Taylor Rule with inertia (Figure 2). Despite this overshoot, the short-run effect on output is a boom and not a slump. The reason for this is that the real interest rate actually falls on impact, due to the rise in the

\footnotetext{
${ }^{10}$ The proofs of the results reported in this paragraph are relatively heavy on algebra. For reasons of length we omit them from the paper but they are available on request. The proof furthermore shows that $d y_{1} / d b^{\prime}>0$, i.e. that output in the impact period rises also relative to its original value.
} 
inflation rate, as can also be seen in the figure. Hence it is not generally true that a permanent debt increase will only boost short-run output if the upward adjustment of the nominal interest rate is delayed, contrary to the impression which might be gained from section 3.2. Rather, the crucial requirement is that the upward adjustment of the real interest rate should be delayed.

Why does the constant money supply rule delay the upward adjustment of the real interest rate whereas the basic Taylor Rule does not? A key point about any Taylor Rule is that it allows the money supply to 'jump'. This is because, as is well known, the nominal interest rate and the money stock are linked through the money demand function, so that the authorities cannot choose arbitrary paths for both variables: if the nominal interest rate is determined by the Taylor Rule, the money supply must become endogenous. We know that a permanent increase in government debt must increase the real and nominal interest rates in the new zero-inflation steady state, and that the higher nominal interest rate must reduce the new steady-state equilibrium level of real money balances. Under the Taylor Rule, this lower level of real balances can be achieved instantly by a downward jump in the money supply with no change in the price level; but under a constant money supply rule, it can only be achieved by an increase in the price level. However, with staggered price-setting, such an increase in the price level takes time. By contrast, the Taylor Rule 'bypasses' the price stickiness in the model by allowing the money supply to jump. ${ }^{11}$

In the case of a temporary increase in government debt, the difference in outcomes under a Taylor Rule and a money supply rule is much less marked. Figure 6 is the counterpart of Figure 4 and shows the effects of a debt increase which lasts for exactly four periods, but now assuming that the money supply is held constant. All other parameter values in this simulation are the same. The responses of output, inflation, the nominal interest rate and real money balances are notably similar.

\footnotetext{
${ }^{11}$ A comparison of Figures 1 and 5 clearly shows the different speeds of adjustment of both nominal and real money balances under the two policies.
} 


\section{Conclusions}

Our general conclusion is that the effectiveness of government debt for demand management is highly sensitive to the monetary policy rule. The standard way to model monetary policy in recent years has been to assume a Taylor Rule. The most basic type of Taylor Rule, however, completely neutralises the ability of a permanent increase in debt to raise short-run output. Government debt can be used effectively within a Taylor Rule regime, but care needs to be exercised over how this is done: either a temporary peg of the nominal interest rate is needed, or some inertia in the Taylor Rule; alternatively, the increase in debt should be chosen to be temporary rather than permanent. If, on the other hand, the monetary policy rule is to set an exogenous path for the money supply, then a permanent increase in debt will increase short-run output without additional qualifications.

These findings are particularly relevant in a period of history such as the recent one. During the 'credit crunch' recession of 2008-9, many governments ran large budget deficits and dramatically increased government debt levels in a deliberate attempt to provide 'fiscal stimulus' to counteract the recession. Such a concerted attempt to use fiscal policy for demand management had not been seen since the 1970s. Our analysis implies that such policies would have been futile if central banks had not cooperated in keeping nominal interest rates low (at almost zero, in fact) while the fiscal stimulus was in progress.

In this paper we have focused on the 'positive' rather than the 'normative' effects of government debt. Being a DGE model, our model also has implications for the effects of debt on welfare, since the impact on the underlying lifetime utility levels of agents can be investigated. However in an overlapping-generations model it is less straightforward to look at welfare than in a so-called 'representative agent' model, because different generations are affected differently by policy. A social welfare function is needed in order to assess optimal policy, and this raises subtle issues which take us beyond our present scope. A careful study of the welfare implications of the use of government debt for demand management we therefore leave for future work. 


\section{Appendix A The Aggregate Demand Function for Labour}

By inverting firm $i$ 's production function we may write its demand for labour as a function of its output: $L_{i t}=Y_{i t}^{1 / \sigma} . Y_{i t}$ is demand-determined and given by (12). If firm $i$ last changed its price $j$ periods ago, then $P_{i t}=X_{t-j}$, so that firm $i$ 's demand for labour is:

$$
L_{i t}=\left(X_{t-j} / P_{t}\right)^{-\theta} Y_{t}
$$

The proportion of firms who last changed their price $j$ periods ago is $(1-\alpha) \alpha$. Summing across $j=0, \ldots, \infty$, we then obtain aggregate labour demand as:

$$
L_{t}=\Sigma_{j=0}^{\infty}(1-\alpha) \alpha^{j}\left(X_{t-j} / P_{t}\right)^{-\theta / \sigma} Y_{t}^{1 / \sigma}
$$

If we define $\tilde{P}_{t} \equiv\left[\Sigma_{j=0}^{\infty}(1-\alpha) \alpha^{j} X_{t-j}^{-\theta / \sigma}\right]^{-\sigma / \theta}$ this can also be written in the form:

$$
L_{t}=Y_{t}^{1 / \sigma}\left(P_{t} / \tilde{P}_{t}\right)^{\theta / \sigma}
$$

which yields the LHS of (19).

Appendix B The Underlying Loglinearised Equations and the Derivation of the Partially-Reduced Form of the Model

$$
\begin{gathered}
p_{t}\left(=\tilde{p}_{t}\right)=\alpha p_{t-1}+(1-\alpha) x_{t} \\
x_{t}=\alpha\left(1+r_{R}\right)^{-1} x_{t+1}+\left(1+r_{R}-\alpha\right)\left(1+r_{R}\right)^{-1}(1-\theta+\theta / \sigma)^{-1}\left[w_{t}+(1 / \sigma-1)\left(\theta p_{t}+y_{t}\right)\right] \\
w_{t}=p_{t}+\sigma^{-1}(\varepsilon-1) y_{t}-\delta z_{t} \\
y_{t}=c_{t}+g_{t} \\
z_{t} \equiv m_{t}-p_{t}-c_{t} \\
z_{t}=-r_{R}^{-1} \hat{i}_{t} \\
a_{t+1}=\beta\left(1+r_{R}\right) a_{t}+\beta\left(1+r_{R}\right) \hat{r}_{t}-\beta \chi\left(1+1 / r_{R}\right) v_{t}
\end{gathered}
$$




$$
\begin{gathered}
\hat{r}_{t}=\hat{i}_{t}-\pi_{t+1}, \\
\pi_{t} \equiv p_{t}-p_{t-1}, \\
a_{t}=\zeta c_{t}-(\zeta-1) \varepsilon l_{t}+\delta(\zeta-1) z_{t}, \\
l_{t}=\sigma^{-1} y_{t}, \\
v_{t}=m_{t}-p_{t+1}+b_{t}^{\prime}, \\
g_{t}-\tau_{t}=\delta(1-\delta)^{-1}\left(1+r_{R}^{-1}\right)\left[\left(1+r_{R}\right)^{-1} b_{t}^{\prime}-b_{t-1}^{\prime}+m_{t}-m_{t-1}\right] .
\end{gathered}
$$

Government spending and taxation are zero in the reference steady state, so their logdeviations are not well defined. Hence we define $g_{t} \equiv G_{t} / Y_{R}, \tau_{t} \equiv T_{t} / Y_{R}$.

To derive the NKPC equation, (24), we first use (A6) to eliminate $w_{t}$ from (A5):

$$
\begin{aligned}
x_{t+1} & -\alpha^{-1}\left(1+r_{R}\right) x_{t} \\
& =-\alpha^{-1}\left(1+r_{R}-\alpha\right)\left[p_{t}+(1-\theta+\theta / \sigma)^{-1}(\varepsilon / \sigma-1) y_{t}-(1-\theta+\theta / \sigma)^{-1} \delta z_{t}\right] .
\end{aligned}
$$

Next, we 'quasi-difference' the price-index equation, (A4), to the same pattern as the LHS of (A17). That is, we advance (A4) by one period, multiply through the original equation by $\alpha^{-1}\left(1+r_{R}\right)$ and then subtract the latter from the former. This gives:

$$
p_{t+1}-\alpha^{-1}\left(1+r_{R}\right) p_{t}=\alpha p_{t}-\left(1+r_{R}\right) p_{t-1}+(1-\alpha)\left[x_{t+1}-\alpha^{-1}\left(1+r_{R}\right) x_{t}\right] .
$$

(A17) can now be used to eliminate the $x$ variables from (A18). The $p$ variables can then be grouped such that they can be replaced by $\pi$ variables, which yields (24).

To derive the IS equation, (25), we substitute (A11), (A13) and (A14) into (A10). Then we use (A7), with $g_{t}$ set to zero, to replace $c_{t}$ by $y_{t}$.

\section{Appendix C The Algebra of the Steady-State Solution}

To solve for the steady state we use the system (31) and (32). This is a slightly more reduced form of the system (24)-(27). Its derivation is described in the main text. Setting 
variables to time-invariant values in (31) and (32), and also setting $\pi=0$, we obtain a pair of equations in $(y, \hat{i})$. Solving these then yields the steady-state solutions (29) and (30).

The common denominator of (29) and (30), namely the bracketed term $\{$.$\} , is at first$ sight of indeterminate sign. Here we show that the sign is in fact negative. Using the definitions of the composite parameters already introduced, we may re-express two of the terms which appear inside $\{$.$\} as follows:$

$$
\begin{gathered}
\beta\left(1+r_{R}\right)-1-\psi=\left[\beta\left(1+r_{R}\right)-1\right] \frac{(1-\delta)(1-1 / \theta)(\sigma / \varepsilon-1)}{1-(1-\delta)(1-1 / \theta)}, \\
{\left[\beta\left(1+r_{R}\right)-1\right] \rho-\psi r_{R}^{-1}=\left[\beta\left(1+r_{R}\right)-1\right] \frac{\left(1-\delta^{2}\right)(1-1 / \theta) \sigma / \varepsilon-1}{1-(1-\delta)(1-1 / \theta)} r_{R}^{-1} .}
\end{gathered}
$$

Recall that $0<\delta, \sigma<1$ and $\theta, \varepsilon>1$. Moreover in the main text we saw that $1+r_{R}>1 / \beta$ when $q$ $<1$. Hence both the expressions in (A19) and (A20) are negative. It then follows that the common denominator, $\{$.$\} , in (29) and (30) is also negative.$

\section{Appendix D Determinacy of Equilibrium Under a Taylor Rule}

The characteristic equation of the system (31)-(33) can be computed as:

$$
a \lambda^{2}+b \lambda+c=0
$$

where $\lambda$ denotes an eigenvalue, $a=1$ and

$$
\begin{gathered}
b=-\left(1+r_{R}\right)\left\{1+\beta-\kappa\left[\psi-v+\left[(\varepsilon / \sigma-1)^{-1} \delta / r_{R}+\rho\right] \phi_{\pi}\right]\right\}+\psi, \\
c=\left(1+r_{R}\right)\left\{\left[1-\kappa(\varepsilon / \sigma-1)^{-1}\left(\delta / r_{R}\right) \phi_{\pi}\right]\left[\beta\left(1+r_{R}\right)-\psi\right]+\kappa\left[v-\beta\left(1+r_{R}\right) \rho+\psi / r_{R}\right] \phi_{\pi}\right\} .
\end{gathered}
$$

Necessary and sufficient conditions for both eigenvalues to lie outside the unit circle are:

$$
\begin{aligned}
& \frac{a+b+c}{a-b+c}>0, \\
& \frac{c-a}{a-b+c}>0 .
\end{aligned}
$$


First, consider the sign of the common denominator $a-b+c$. By manipulation of the terms for $b$ and $c$, we can obtain:

$$
\begin{gathered}
a-b+c=\left(2+r_{R}\right)\left[1+\beta\left(1+r_{R}\right)-\psi\right] \\
+\left(1+r_{R}\right) \kappa\left(v-\psi+\left\{v-\left[1+\beta\left(1+r_{R}\right)\right]\left[(\varepsilon / \sigma-1)^{-1} \delta / r_{R}+\rho\right]\right\} \phi_{\pi}\right. \\
\left.+\left[(\varepsilon / \sigma-1)^{-1} \delta / r_{R}+1 / r_{R}\right] \phi_{\pi} \psi\right) .
\end{gathered}
$$

We now claim that $a-b+c>0$ for $\delta$ sufficiently close to zero. As $\delta \rightarrow 0,1+r_{R} \rightarrow \beta^{1}$, as was shown in the main text (see the discussion of (23)). This implies that $\psi \rightarrow 0$ (from the definition of $\psi$ ). Hence the term on the first line of $(\mathrm{A} 24) \rightarrow\left(1+\beta^{1}\right) 2$, which is positive. Concerning the term on the second line of (A24), note that $v-\psi$ is always positive (from the definitions of $v$ and $\psi$ ). The term \{.\} at first sight has an ambiguous sign. However, as $\delta \rightarrow 0$, $v$ remains strictly positive, while $\rho \rightarrow 0$ (see the definitions of $v$ and $\rho$ ). Therefore $\{$.$\} is$ unambiguously positive for $\delta$ sufficiently close to zero. Concerning the term on the third line of (A24), we note that it is always positive. This set of observations proves our claim.

Second, consider the sign of $c-a$, the numerator of (A23). We can write $c-a$ as:

$$
\begin{gathered}
c-a=\left(1+r_{R}\right)\left(\beta\left(1+r_{R}\right)-\left(1+r_{R}\right)^{-1}-\psi\right. \\
+\kappa\left\{v-\beta\left(1+r_{R}\right)\left[(\varepsilon / \sigma-1)^{-1} \delta / r_{R}+\rho\right]\right\} \phi_{\pi} \\
\left.\kappa\left[(\varepsilon / \sigma-1)^{-1} \delta / r_{R}+1 / r_{R}\right] \phi_{\pi} \psi\right) .
\end{gathered}
$$

We now claim that $c$ - $a>0$ for $\delta$ sufficiently close to zero. As $\delta \rightarrow 0,1+r_{R} \rightarrow \beta^{1}$, as was shown in the main text (see the discussion of (23)). This implies that $\psi \rightarrow 0$ (from the definition of $\psi$ ). Hence the term on the first line of $(\mathrm{A} 25) \rightarrow \beta^{1}(1-\beta)$, which is positive. The term on the second line of (A25) at first sight has an ambiguous sign. However, as $\delta \rightarrow 0, v$ remains strictly positive, while $\rho \rightarrow 0$ (see the definitions of $v$ and $\rho$ ). Therefore $\{$.$\} is$ unambiguously positive for $\delta$ sufficiently close to zero. Concerning the term on the third line of (A25), we note that it is always positive. This set of observations proves our claim. 
From the foregoing it follows that, for $\delta$ sufficiently close to zero, condition (A23) is satisfied with no further parameter restrictions. It also follows that, for $\delta$ sufficiently close to zero, condition (A22) will be satisfied if and only if $a+b+c>0$. Now, eliminating $(\psi, \rho, v)$ using their definitions, with some manipulation we can express $a+b+c$ as:

$$
\begin{gathered}
a+b+c=[1-(1-\delta)(1-1 / \theta)]^{-1}\left(1+r_{R}\right) \kappa \zeta^{-1}\left[\beta\left(1+r_{R}\right)^{2}-1\right] r_{R}^{-1} \\
\times\left(\phi_{\pi}-\frac{r_{R}}{\beta\left(1+r_{R}\right)^{2}-1}-\frac{1}{\kappa} \frac{(1-\delta)(1-1 / \theta)(1-\sigma / \varepsilon)}{1-(1-\delta)(1-1 / \theta) \sigma / \varepsilon} \frac{\beta\left(1+r_{R}\right)-1}{\beta\left(1+r_{R}\right)^{2}-1} \frac{r_{R}^{2}}{1+r_{R}}\right) .
\end{gathered}
$$

$a+b+c$ is clearly positive if and only if the term on the second line is positive. Thus, for $\delta$ sufficiently small, the necessary and sufficient condition for determinacy is that:

$$
\phi_{\pi}>\frac{r_{R}}{\beta\left(1+r_{R}\right)^{2}-1}+\frac{1}{\kappa} \frac{(1-\delta)(1-1 / \theta)(1-\sigma / \varepsilon)}{1-(1-\delta)(1-1 / \theta) \sigma / \varepsilon} \frac{\beta\left(1+r_{R}\right)-1}{\beta\left(1+r_{R}\right)^{2}-1} \frac{r_{R}^{2}}{1+r_{R}}
$$

As the probability of price non-adjustment, $\alpha$, increases, $\kappa$ falls and so the critical value of $\phi_{\pi}$ for determinacy increases. Condition (A27) is sketched in the diagram in the main text which illustrates Proposition 2.

\section{Appendix E Equations and Calibration of the Non-Linear Model}

The non-linear model that we use in the simulations is described by the following equations. (Some symbols here have different definitions from those in the main text. This is noted where relevant.)

\section{Household sector}

The household sector is described by the aggregation of the first-order conditions of the household's problem, that is

$$
\begin{gathered}
M_{t} / P_{t} C_{t} \quad\left(\equiv Z_{t}\right)=\delta(1-\delta)^{-1}\left(1+i_{t}\right) / i_{t} \\
W_{t} / P_{t}=(1-\delta)^{-1} Z_{t}^{-\delta} \eta L_{t}^{\varepsilon-1} \\
C_{t+1}-Z_{t+1}^{-\delta}(\eta / \varepsilon) L_{t+1}^{\varepsilon}=\beta\left(1+r_{t}\right)\left[C_{t}-Z_{t}^{-\delta}(\eta / \varepsilon) L_{t}^{\varepsilon}\right]-(1-\delta)(1-\beta q)(1 / q-1) V_{t} .
\end{gathered}
$$




$$
V_{t}=M_{t} / P_{t+1}+B_{t}^{\prime}=m_{t} / \pi_{t+1}+B_{t}^{\prime} .
$$

where $m_{t} \equiv M_{t} / P_{t}$ and $\pi_{t} \equiv P_{t} / P_{t-1}$.

Prices

The firm's price setting equation (14) needs to be rearranged. It is easy to show that equation (14)

$$
X_{t}^{1-\theta+\theta / \sigma}=\frac{\theta}{\theta-1} \frac{\sum_{j=0}^{\infty} \alpha^{j} \Delta_{t, t+j} \frac{1}{\sigma} Y_{t+j}^{1 / \sigma} W_{t+j} P_{t+j}^{\theta / \sigma-1}}{\sum_{j=0}^{\infty} \alpha^{j} \Delta_{t, t+j} Y_{t+j} P_{t+j}^{\theta-1}}
$$

can be written in a recursive formulation as

$$
\begin{gathered}
x_{t}^{1-\theta+\theta / \sigma}=\frac{\theta}{\theta-1} \frac{\psi_{t}}{\phi_{t}} . \\
\psi_{t}=\frac{1}{\sigma} Y_{t}^{1 / \sigma} w_{t}+\frac{\alpha}{1+r_{t}} \pi_{t+1}^{\theta / \sigma} \psi_{t+1} . \\
\phi_{t}=Y_{t}+\frac{\alpha}{1+r_{t}} \pi_{t+1}^{\theta-1} \phi_{t+1} .
\end{gathered}
$$

where $x_{t} \equiv X_{t} / P_{t}$ and $w_{t} \equiv W_{t} / P_{t}$

The evolution of the price index can also be written in a recursive formulation as

$$
\begin{gathered}
P_{t}=\left[(1-\alpha) \int_{0}^{\infty} \alpha^{j} X_{t-j}^{1-\theta} d j\right]^{1 /(1-\theta)} . \\
P_{t}=\left[\alpha P_{t-1}^{1-\theta}+(1-\alpha) X_{t}^{1-\theta}\right]^{1 /(1-\theta)} \Rightarrow \quad 1=\alpha \pi_{t}^{\theta-1}+(1-\alpha) x_{t}^{1-\theta}
\end{gathered}
$$

Aggregate labour demand

Aggregate labour demand is given by

$$
L_{t}=\int_{0}^{1} L_{i, t} d i=\int_{0}^{1} Y_{i, t}^{1 / \sigma} d i=\int_{0}^{1}\left(\frac{P_{i, t}}{P_{t}}\right)^{-\theta / \sigma} Y_{t}^{1 / \sigma} d i=Y_{t}^{1 / \sigma} \int_{0}^{1}\left(\frac{P_{i, t}}{P_{t}}\right)^{-\theta / \sigma} d i=Y_{t}^{1 / \sigma} S_{t}
$$

where $s_{t} \equiv \int_{0}^{1}\left(\frac{P_{i, t}}{P_{t}}\right)^{-\theta / \sigma} d i$ is an index of the price dispersion in period $t$. Schmitt-Grohé and Uribe (2007) show that $s_{t}$ is bounded below by one, so that $s_{t}$ represents the resource costs due to relative price dispersion under the Calvo mechanism. Indeed, the higher $s_{t}$, the more labour is needed to produce a given level of output. Note that $s_{t}$ does not affect the real 
variables up to the first order if inflation is zero in steady state (see Ascari, 2004). The dynamics of $s_{t}$ can be written in a recursive formulation as

$$
s_{t}=\int_{0}^{1}\left(\frac{P_{i, t}}{P_{t}}\right)^{-\theta / \sigma} d i=(1-\alpha)\left(\frac{X_{t}}{P_{t}}\right)^{-\theta / \sigma}+\alpha \pi_{t}^{\theta / \sigma} s_{t-1}=(1-\alpha) x_{t}^{-\theta / \sigma}+\alpha \pi_{t}^{\theta / \sigma} s_{t-1} \text {. }
$$

\section{Government sector}

Fiscal policy is described by (17), that using $m_{t} \equiv M_{t} / P_{t}$, can be written as

$$
G_{t}-T_{t}=\left(1+r_{t}\right)^{-1} B_{t}^{\prime}-B_{t-1}^{\prime}+m_{t}-m_{t-1} / \pi_{t}
$$

while monetary policy is described by the following inflation targeting Taylor Rule

$$
1+i_{t}=e^{\bar{i}}\left(\frac{\pi_{t}}{\bar{\pi}}\right)^{\phi_{\pi}}
$$

where $\bar{\pi}$ is the inflation target of the central bank.

General equilibrium conditions

To close the model, we just need to add the goods market equilibrium condition (18)

$$
Y_{t}=C_{t}+G_{t}
$$

the definition of the auxiliary variable $\mathrm{Z}$

$$
Z_{t} \equiv m_{t} / C_{t}
$$

the relationship between the nominal and the real interest rate,

$$
1+r_{t} \equiv \frac{1+i_{t}}{\pi_{t+1}}
$$

and the definition of the rate of growth of money supply, i.e. $\mu_{t}$,

$$
\mu_{t} \equiv \frac{m_{t} \pi_{t}}{m_{t-1}}
$$


The model is then composed of the following 16 equations: (4)-(6), (18), (20), (A28)(A38), that describe the dynamics of the following 16 variables: $C_{t}, Z_{t}, L_{t}, V_{t}, r_{t}, i_{t}, w_{t}, x_{t}, \psi_{t}$, $\phi_{t}, Y_{t}, \pi_{t}, s_{t}, m_{t}, T_{t}, \mu_{t}$

It is immediate to note that there is only one state variable: $s_{t}$. Moreover its steady state depends just on the steady state value of the inflation rate, since

$$
\bar{s}=\frac{(1-\alpha) \bar{x}^{-\theta / \sigma}}{1-\alpha \bar{\pi}^{\theta / \sigma}}=\frac{(1-\alpha)\left(\frac{1-\alpha \bar{\pi}^{\theta-1}}{1-\alpha}\right)^{-\theta / \sigma(1-\theta)}}{1-\alpha \bar{\pi}^{\theta / \sigma}} .
$$

Hence, an immediate jump to the new steady state where the value of $\bar{\pi}$ does not change is compatible with the inertial adjustment of $s_{t}$ implied by (A33), since $s_{t}$ simply does not move at all.

\section{Calibration}

$q=1-1 / 120$, such that the expected working life is 30 years, as in Leith and Wren-Lewis (2006). $\alpha=0.75, \sigma=1, \theta=10, \beta=(0.96)^{0.25}, \delta=0.01, \varepsilon=2, \phi_{\pi}=1.5$, while $\eta$ is calibrated such that $Y$ is normalized to 1 in a zero-inflation steady state where $\bar{B}=\bar{G}=0$. In the policy experiments, $\bar{\pi}=1, \bar{B}=\bar{G}=0$ in the initial steady state; then $\bar{B}$ increases unexpectedly to 0.01 .

\section{Appendix F Signs of the Coefficients in Equations (35) and (36)}

(i) $1-\xi \phi_{\pi}$. From what was noted in the main text, as $\delta \rightarrow 0, \xi \rightarrow 0$. This is sufficient to ensure $1-\xi \phi_{\pi}>0$, but we also need to check that $\phi_{\pi}$ remains in the range which ensures determinacy. From (A27), the critical value above which $\phi_{\pi}$ must lie for determinacy tends to 1 as $\delta \rightarrow 0$. Hence for any given $\phi_{\pi}>1$, for $\delta$ sufficiently close to 0 , both $1-\xi \phi_{\pi}>0$ and determinacy hold.

(ii) $\beta\left(1+r_{R}\right)-\psi$. From what was noted in the main text, as $q \rightarrow 1, \beta\left(1+r_{R}\right)-\psi \rightarrow 1 . \beta\left(1+r_{R}\right)-\psi$ is therefore positive for $q$ sufficiently close to 1 . 
(iii) $v+\psi r_{R}^{-1}-\beta\left(1+r_{R}\right) \rho$. From what was noted in the main text, as $\delta \rightarrow 0, \psi, \rho \rightarrow 0$ while $\nu, r_{R}$ tend to strictly positive, finite values. Hence $v+\psi r_{R}^{-1}-\beta\left(1+r_{R}\right) \rho$ is positive for $\delta$ sufficiently close to 0 . 


\section{References}

Ascari, G. (2004) 'Staggered Prices and Trend Inflation: Some Nuisances', Review of Economic Dynamics, 7(3), 642-667

Ascari, G. and Rankin, N. (2007) 'Perpetual Youth and Endogenous Labour Supply: A Problem and a Possible Solution', Journal of Macroeconomics 29(4), 708-723

Bénassy, J.-P. (2005) 'Interest Rate Rules, Price Determinacy and the Value of Money in a Non-Ricardian World', Review of Economic Dynamics 8(3), 651-667

Bénassy, J.-P. (2007a) 'IS-LM and the Multiplier: A Dynamic General Equilibrium Model', Economics Letters 96, 189-195

Bénassy, J.-P. (2007b) Money, Interest and Policy: Dynamic General Equilibrium in a NonRicardian World, Cambridge, MA: MIT Press

Blanchard, O.J. (1985) 'Debt, Deficits and Finite Horizons', Journal of Political Economy 93(2), 223-247

Brock, W.A. (1974) 'Money and Growth: The Case of Long-Run Perfect Foresight', International Economic Review 15(3), 750-777

Calvo, G. (1983) 'Staggered Prices in a Utility-Maximising Framework', Journal of Monetary Economics 12(3), 383-398

Chadha, J. and Nolan, C. (2007) 'Optimal Simple Rules for the Conduct of Monetary and Fiscal Policy', Journal of Macroeconomics 29(4), 665-689

Christiano, L. Eichenbaum, M. and Rebelo, S. (2009) 'When Is the Government Spending Multiplier Large?', NBER Working Paper no. 15394

Diamond, P.A. (1965) 'National Debt in a Neoclassical Growth Model', American Economic Review 55(5), 1126-1150

Eggertsson, G. B. (2009) 'What Fiscal Policy Is Effective at Zero Interest Rates?', Federal Reserve Bank of New York Staff Report no. 402

Galí, J. López-Salido, D. and Vallés, J. (2007) 'Understanding the Effects of Government Spending on Consumption', Journal of the European Economic Association 5(1), 227270

Greenwood, J., Hercowitz, Z. and Huffman, G.W. (1988) 'Investment, Capacity Utilisation and the Real Business Cycle', American Economic Review 78(3), 402-417

Heijdra, B.J. and Ligthart, J.E. (2000) 'The Dynamic Effects of Tax Policy in an Overlapping-Generations Model', Oxford Economic Papers 52(4), 677-701

Kirsanova, T., Leith, C. and Wren-Lewis, S. (2009) 'Monetary and fiscal policy interaction: The current consensus assignment in the light of recent developments', Economic Journal, 119 (541), F482-F496 
Leith, C. and von Thadden, L. (2008) 'Monetary and Fiscal Policy Interactions in a New Keynesian Model with Capital Accumulation and Non-Ricardian Consumers', Journal of Economic Theory 140(1), 279-313

Leith, C. and Wren-Lewis, S. (2000) 'Interactions between monetary and fiscal policy rules', Economic Journal, 110(462), 93-108

Leith, C. and Wren-Lewis, S. (2006) 'Compatibility between Monetary and Fiscal Policy under EMU’, European Economic Review 50(6), 1529-1556

Leith, C. and Wren-Lewis, S. (2008). 'Interactions between monetary and fiscal policy under flexible exchange rates', Journal of Economic Dynamics and Control, 32(9), 28542882.

Piergallini, A. (2006) 'Real Balance Effects and Monetary Policy', Economic Inquiry 44(3), 497-511

Schmitt-Grohé, S. and Uribe, M. (2007) 'Optimal Simple and Implementable Monetary and Fiscal Rules', Journal of Monetary Economics, 54(6), 1702-1725.

Taylor, J.B. (1993) 'Discretion versus Policy Rules in Practice', Carnegie-Rochester Conference Series on Public Policy 39, 195-214

Woodford, M. (2003) Interest and Prices, Princeton: Princeton University Press

Woodford, M. (2010), 'Simple Analytics of the Government Expenditure Multiplier', mimeo, Columbia University. 

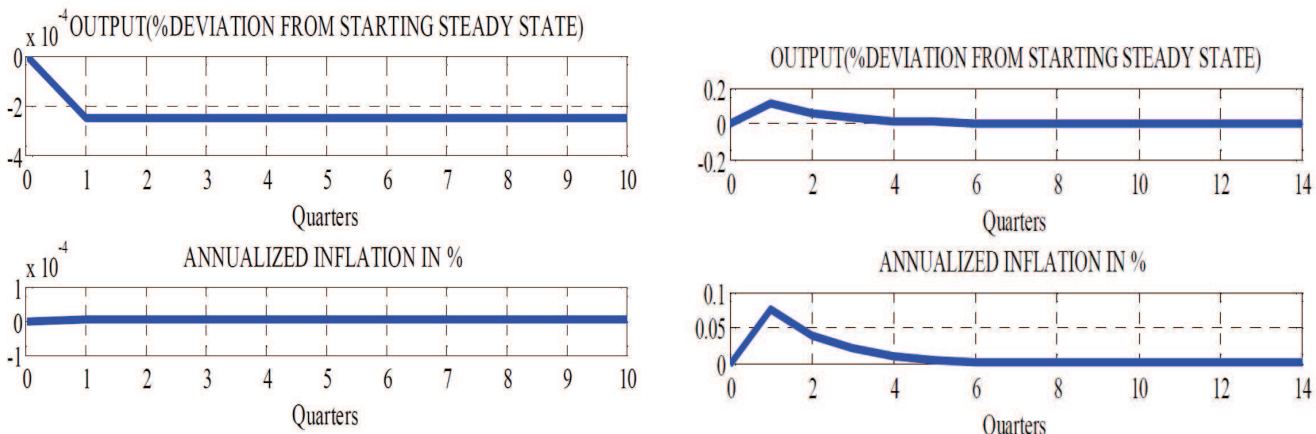

ANNUALIZED INFLATION IN \%

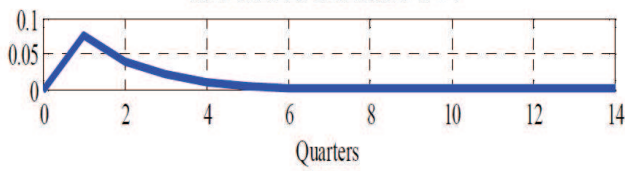

ANNUALIZED NOMINAL INTEREST RATE IN \%

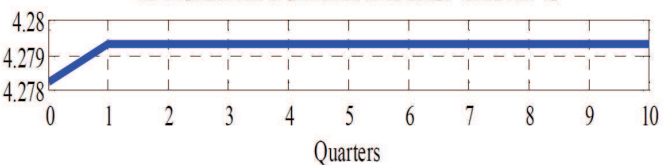

ANNUALIZED REAL INTEREST RATE IN \%

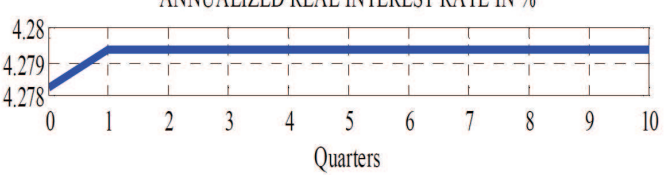

ANNUALIZED MONEY GROWTH RATE IN \%

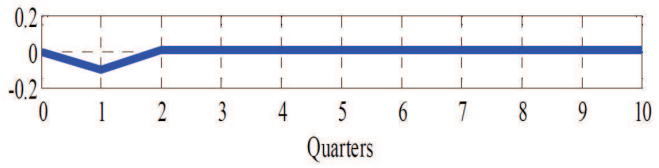

REAL MONEY BALANCES (\%DEVIATION FROM STARTING STEADY STATE)

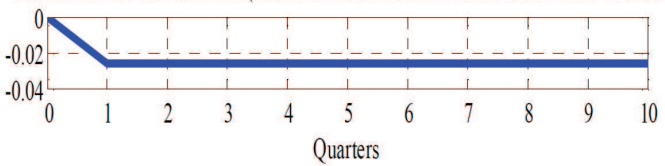

REAL WEALTH

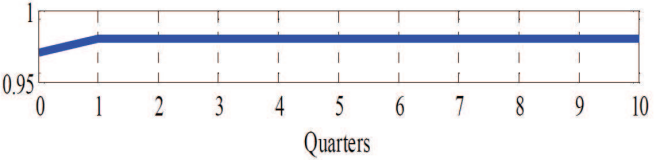

REAL TAXES

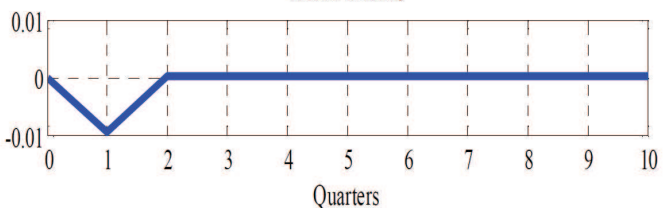

Figure 1

Effects of a permanent debt increase under the basic Taylor Rule

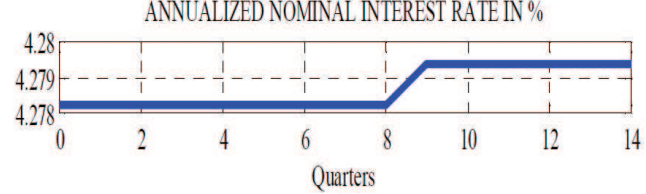

ANNUALIZED REAL INTEREST RATE IN \%

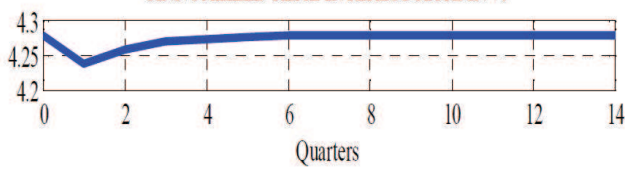

ANNUALIZED MONEY GROWTHRATE IN \%

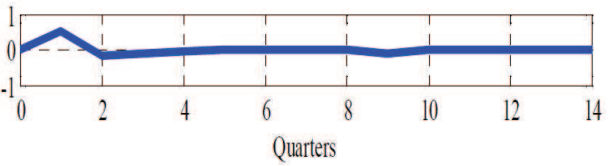

REAL MONEY BALANCES (\%DEVIATION FROM STARTING STEADY STATE)

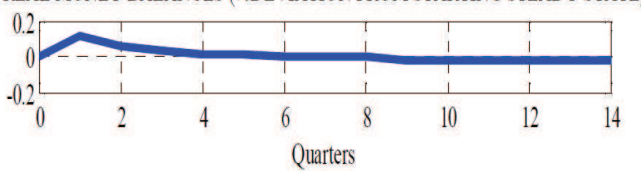

REAL WEALTH

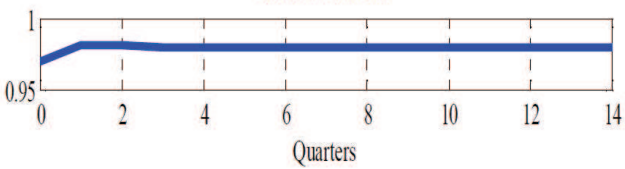

REAL TAXES

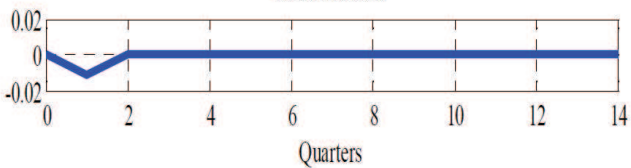

Figure 2

Effects of a permanent debt increase under a Taylor Rule with a temporary (8-period) nominal interest-rate peg 

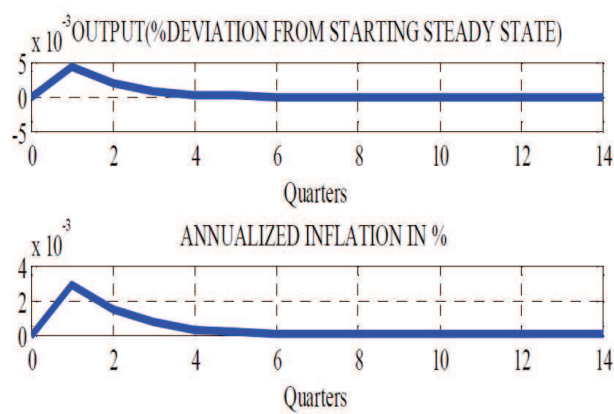

ANNUALIZED NOMINAL INTEREST RATE IN\%

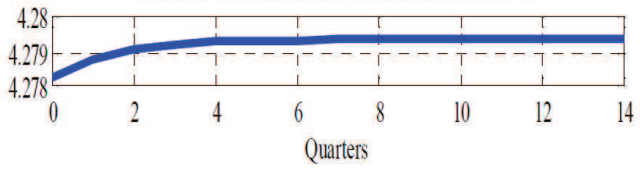

ANNUALIZED REAL INTEREST RATE IN \%

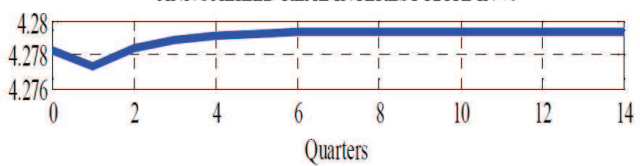

ANNUALIZED MONEY GROWTH RATE IN \%

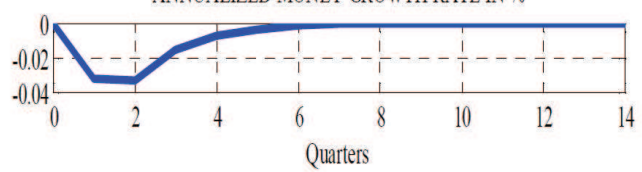

REAL MONEY BALANCES (\%DEVIATION FROM STARTING STEADY STATE)

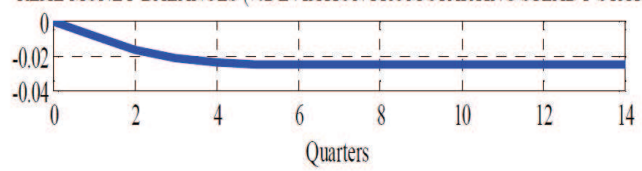

REAL WEALTH

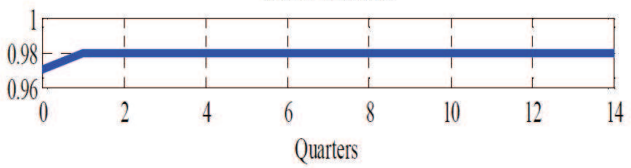

REAL TAXES

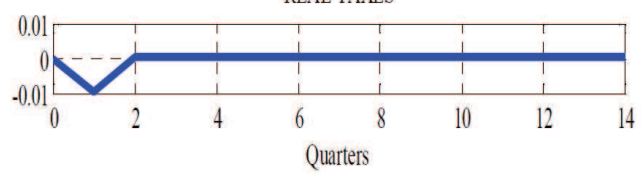

Figure 3

Effects of a permanent debt increase under the Taylor Rule with inertia
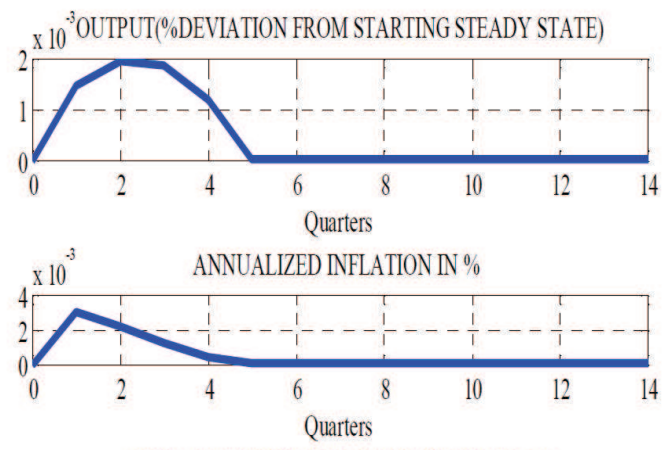

ANNUALIZED NOMINAL INTEREST RATE IN \%

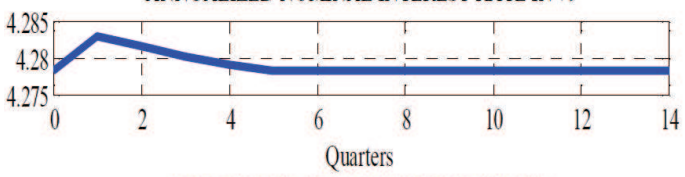

ANNUALIZED REAL INTEREST RATE N $\%$

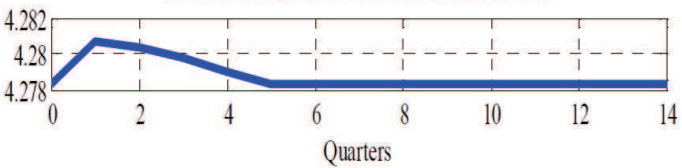

ANNUALIZED MONEY GROWTH RATE IN \%

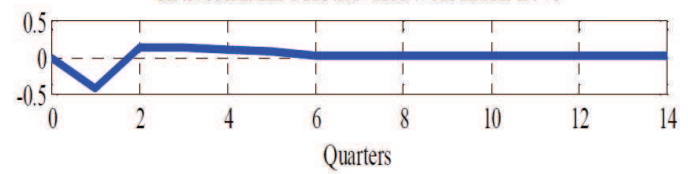

REAL MONEY BALANCES (\%DEVIATION FROM STARTING STEADY STATE)

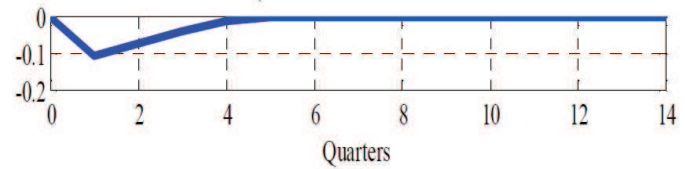

REAL WEALTH

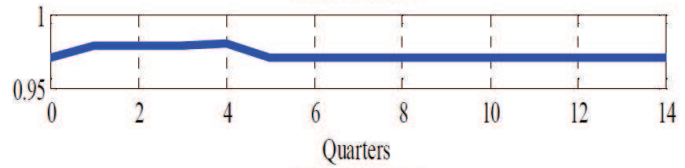

REAL TAXES

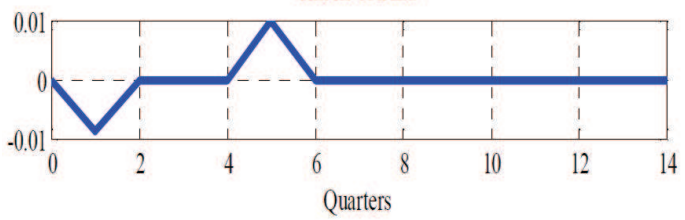

Figure 4

Effects of a temporary (4-period) debt increase under the basic

Taylor Rule 


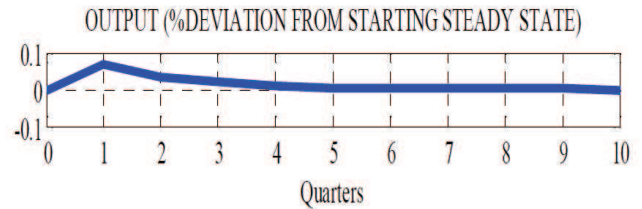

ANNUALZED NFLATION N \%

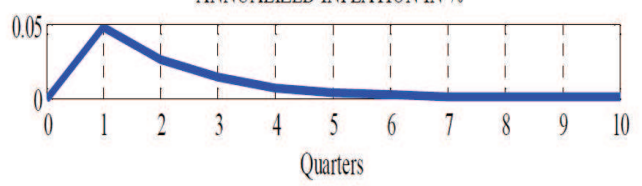

ANNUALLZED NOMINAL INTEREST RATE IN \%

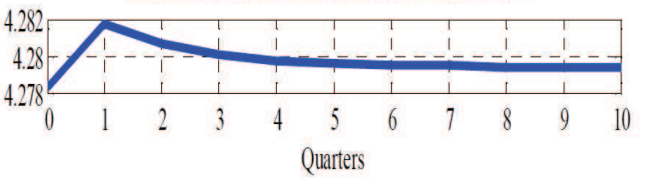

ANNUALIZED REAL INTEREST RATE IN\%

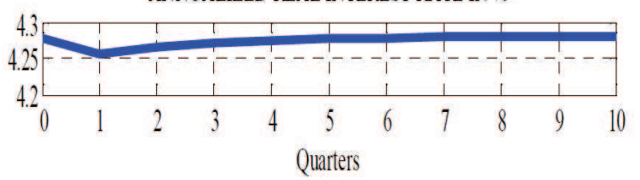

ANNUALIZED MONEY GROWTH RATE IN \%

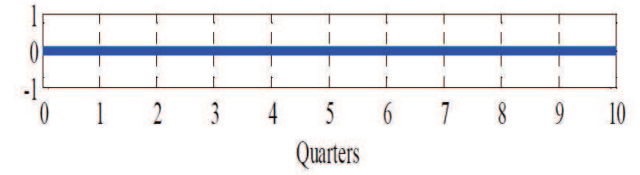

REAL MONEY BALANCES (\%DEVIATION FROM STARTING STEADY STATE)

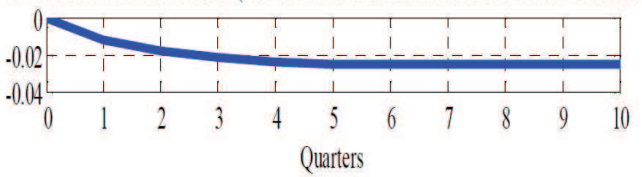

REAL WEALTH

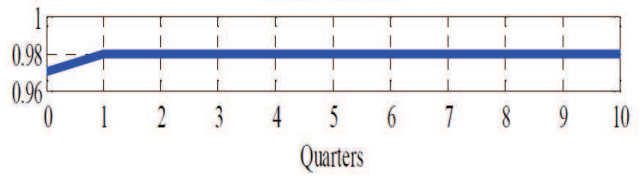

REALTAXES

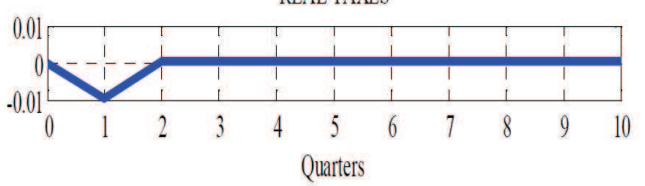

Figure 5

Effects of a permanent debt increase under a constant money supply
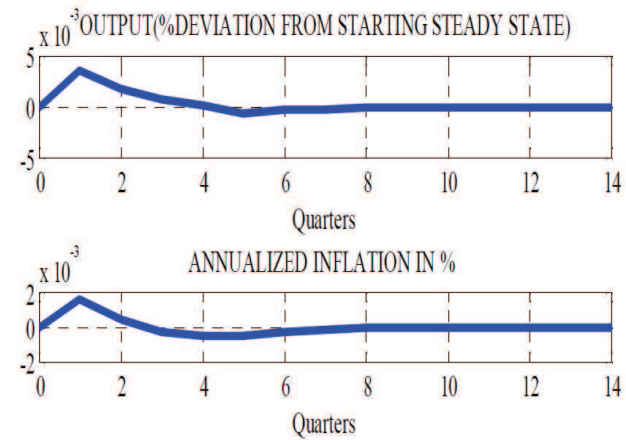

ANNUALLZED NOMINAL NTEREST RATE IN \%

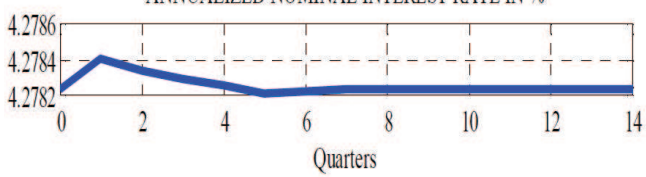

ANNUALIZED REAL INTEREST RATE N \%

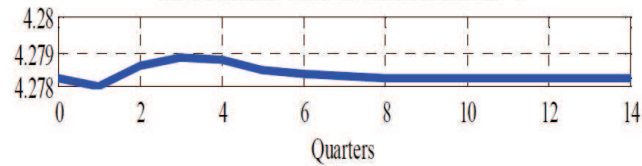

ANNUALIZED MONEY GROWTH RATE IN \%

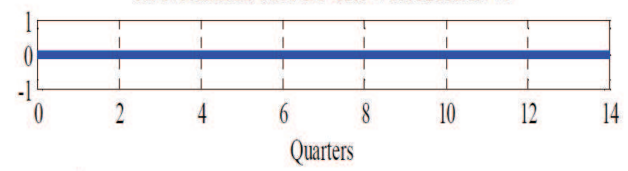

REAL MONEY BALANCES (\%DEVIATION FROM STARTING STEADY STATE)

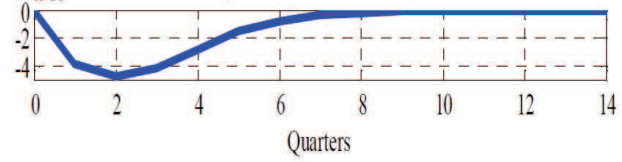

REAL WEALTH

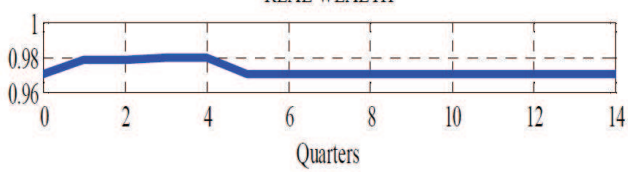

REAL TAXES

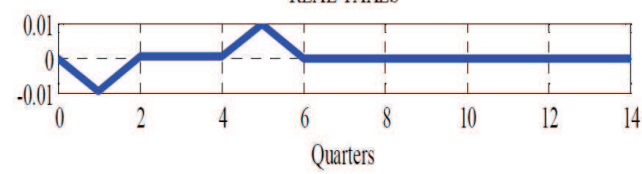

Figure 6

Effects of a temporary (4-period) debt increase under a constant money supply 